\title{
DESARRAIGAMENTO E A PROTEÇÃO DOS MIGRANTES NA LEGISLAÇÃO INTERNACIONAL DOS DIREITOS HUMANOS*
}

\author{
DISPLACEMENT AND MIGRANT'S PROTECTION IN \\ INTERNATIONAL HUMAN RIGHTS LAW
}

Por A.A. Cançado Trindade**

RESUMO: I. Observações Preliminares. II. O Drama do desarraigamento e a crescente necessidade de proteção dos migrantes. III. Princípios básicos sobre deslocados internos. 1. Nível Global (Nações Unidas). 2. Nível Regional. IV. Princípios Básicos de Migrações. V. A Proteção de Migrantes na Jurisprudência do Direito Internacional. 1. Sistema de Direitos Humanos Europeu. 2. Sistema de Direitos Humanos Inter-americano. a) A Opinião Consultiva relativa ao Direito à Informação sobre Assistência Consular no âmbito das garantias do Devido Processo Legal (1999). b) A Opinião Consultiva sobre a Condição Jurídica e os Direitos de Migrantes Indocumentados (2003). VI. A Proteção de migrantes em sistemas de Rapporteur. VII. Responsabilidade Estatal: Variações sobre um antigo tema do Direito Internacional. VIII. Reflexões finais sobre o assunto.

PALAVRAS-CHAVE: desarraigamento; migração; direito internacional dos direitos humanos.

* Tradução autorizada pelo Autor da versão original em inglês (UPROOTEDNESS AND THE PROTECTION OF MIGRANTS IN THE INTERNATIONAL LAW OF HUMAN RIGHTS) feita por Gabriel Gualano de Godoy, Bacharel
ABSTRACT: I. Preliminary Observations. II. The Drama of Uprootedness and the Growing Need of Protection of Migrants. III. Basic Principles on Internal Displacement. 1. Global (United Nations) Level. 2. Regional Level. IV. Basic Principles on Migrations. V. The Protection of Migrants in International Case-Law. 1. European Human Rights System. 2. Inter-American Human Rights System. a) The Advisory Opinion on the Right to Information on Consular Assistance in the Framework of the Due Process of Law (1999). b) The Advisory Opinion on the Juridical Condition and Rights of Undocumented Migrants (2003). VI. The Protection of Migrants in Rapporteur Systems. VII. State Responsibility: Variations on an Old Theme of International Law. VIII. Final Reflections on the Matter.

KEYWORDS: uprootedness; migration; international human rights law.

e Mestre em Direito pela UFPR, pesquisador do Núcleo de Direitos Humanos da mesma Universidade.

** Ph.D. (Cambridge); Ex-Presidente da Corte Inter-americana de Direitos Humanos; Professor de Direito Internacional da Universidade de Brasília, Brasil; Membro do Institut de Droit International. 


\section{OBSERVAÇÕES PRELIMINARES}

Começo a aula inaugural da Sessão de Estudos Anuais de 2007 invocando minha histórica e contínua ligação de grande afeto pelo Instituto de Direitos Humanos em Estrasburgo. Precisamente aqui, nesse mesmo auditório Carré de Malberg da Universidade de Estrasburgo, tive a honra de receber em 1974, das mãos do próprio René Cassin, meu diploma do Instituto. Mais uma vez, nesse mesmo auditório, fui recebido em 1997, como recém-eleito membro do Institut de Droit International. Tive o privilégio de conhecer e acompanhar o trabalho, durante as últimas três décadas de todos os sucessivos Presidentes e Secretários-Gerais do Instituto Internacional de Direitos Humanos, aos quais permaneci como fiel e constante colaborador do outro lado do Atlântico. Um deles, recentemente falecido (no dia 22 de Março de 2007), foi o Professor Alexandre-Charles Kiss, um jurista visionário e inspirador, que reverencio neste momento. Este auditório está cheio da história do Instituto de Estrasburgo e de minha própria vida acadêmica, portanto não posso ministrar esta aula inaugural sem emoções.

Primeiramente, deixem-me expressar um alerta firme contra os efeitos negativos do fato que, em um mundo "globalizado" - o novo eufemismo em voga - as fronteiras estão abertas para o capital, bens e serviços, mas, lamentavelmente, não a seres humanos. Economias nacionais estão abertas ao capital especulativo, ao mesmo tempo em que as conquistas trabalhistas erodem. Crescentes segmentos da população tornam-se marginalizados e excluídos do "progresso" material. Lições do passado parecem estar esquecidas e o sofrimento de gerações anteriores parece em vão. O presente "estado das coisas" parece estar destituído de um sentido histórico. A essa "des-historização" da vida adiciona-se a adoração ao mercado, reduzindo os seres humanos a meros agentes de produção (ironicamente, em meio a um crescente desemprego em distintas latitudes).

Como resultado dessa tragédia contemporânea - essencialmente provocada pelo homem - perfeitamente evitável se a solidariedade humana tivesse primazia sobre o egoísmo individual - emerge e intensifica-se o novo fenômeno de fluxos massivos de migrações forçadas - nas quais milhões de indivíduos buscam fugir não mais de perseguições políticas individuais, mas predominantemente da fome, miséria e de conflitos armados - com graves consequiências e implicações para a aplicação das normas internacionais de proteção ao ser humano.

Uma década atrás, em um estudo que preparei para o Instituto Inter-Americano de Direitos Humanos (na Costa Rica, em 1998), publicado na Guatemala em 2001, propus um enfoque de Direitos Humanos para entender os fluxos de migrações forçadas - distinto dos estudos clássicos sobre o tema (cujo foco era uma abordagem estritamente histórica, ou até econômica) - e com grande atenção destinada à experiência de seres humanos em estado de grave vulnerabilidade ${ }^{1}$. Na ocasião, percebi que era digno destacar que:

A.A. Cançado Trindade, Elementos para un Enfoque de Derechos Humanos del Fenómeno de los Flujos Migratorios Forzados (Estudo de Julho de 1998 preparado para o IIHR), Cidade da Guatemala, OIM/IIDH, Set. 2001, pp. 1-57. 
Os avanços [nesse campo] somente serão alcançadas por meio de uma radical mudança de pensamento. Em uma escala de valores, considerações de ordem humanitária devem prevalecer sobre considerações de ordem econômica ou financeira, sobre a alegada proteção do mercado de trabalho e sobre a rivalidade de grupos sociais. Há, definitivamente, forte necessidade de situar o ser humano no seu devido lugar, certamente acima de capitais financeiros, bens e serviços. Esse é o maior desafio do mundo 'globalizado' em que vivemos, na perspectiva dos Direitos Humanos².

Nesta aula inaugural da presente Sessão de Estudo Anual de 2007 do Instituto Internacional de Direitos Humanos, aqui em Estrasburgo, devo retomar o assunto, que se tornou bastante atual, com o propósito de identificar e reunir os elementos, acumulados em anos recentes, que permitem avançar com o enfoque anteriormente mencionado, próprio dos Direitos Humanos, no que diz respeito às considerações do fenômeno contemporâneo das migrações forçadas. Para este fim, devo relatar o drama dos dessarraigados e a sua crescente necessidade de proteção, e identificar os princípios básicos aplicáveis nesse novo domínio da proteção do indivíduo; devo, ainda, revisar a crescente jurisprudência sobre o assunto (de ambas as Cortes Européia e Inter-americana de Direitos Humanos, assim como outras iniciativas de proteção das Nações Unidas e em níveis regionais; as implicações do assunto no que diz respeito à responsabilidade dos Estados; e sua importância para a comunidade internacional como um todo). Dessa forma, estará aberto o caminho para a apresentação de minhas considerações finais sobre o assunto em questão.

\footnotetext{
2 Ibid., p. 26.
}

\section{O DRAMA DO}

DESSARRAIGAMENTO E A CRESCENTE NECESSIDADE DE PROTEÇÃO DOS MIGRANTES

Um alerta vem sendo corretamente divulgado: a humanidade somente alcançará verdadeiro progresso quando avançar no que diz respeito à emancipação humana ${ }^{3}$. Não deve ser esquecido que o Estado foi concebido para a realização do bem comum ${ }^{4}$. Nenhum Estado deve considerar-se acima da lei, e as normas têm, como último beneficiário, o ser humano; em suma, o Estado existe para o ser humano e não o contrário.

Paradoxalmente, a expansão da "globalização" tem sido acompanhada pari passu pela erosão da capacidade dos Estados de proteger os direitos econômicos, sociais e culturais das pessoas sob sua jurisdição e, da mesma forma, as crescentes necessidades de proteção dos refugiados, pessoas deslocadas e migrantes, nessa primeira década do século XXI, requer solidariedade em escala universal $^{5}$. Esse paradoxo parece ser um tanto

3 J. Maritain, Los Derechos del Hombre y la Ley Natural, Buenos Aires, Ed. Leviatán, 1982 (reimpr.), pp. 12, 18, 38, 43, 50, 94-96 and 105-108. Para J. Maritain, "a pessoa humana transcende o Estado", por ter "um destino superior ao tempo"; ibid., pp. 81-82. Em os "fins humanos do poder", cf. Ch. de Visscher, Théories et réalités en Droit international public, 4o. rev. ed., Paris, Pédone, 1970, pp. 18-32 et seq..

4 Por Estado, aqui, entendemos o Estado em uma sociedade democrática, ou seja, o Estado que assegura o respeito pelos Direitos Humanos, que é voltado para o bem comum, e cujos poderes políticos, separadamente, são regidos por uma Constituição e pela supremacia da Lei, com efetivas garantias processuais de Direitos Humanos e liberdades fundamentais.

S. Ogata, Challenges of Refugee Protection (Declaração na Universidade de Havana, 11.05.2000), Havana/Cuba, ACNUR, 2000, pp. 7-9 (circulação interna); 
trágico, tendo em mente os avanços da ciência e da tecnologia nas décadas passadas que, infelizmente, foram incapazes de reduzir ou erradicar o egoísmo humano ${ }^{6}$.

Tragicamente, o progresso material de alguns tem sido acompanhado pelo fechamento das fronteiras para os seres humanos e o aparecimento de novas e cruéis formas de servidão humana (tráfico clandestino de pessoas, prostituição forçada, exploração de trabalho, entre outros), das quais migrantes sem documentos são freqüentes vítimas. Os crescentes controles e as atuais dificuldades impostas aos migrantes levaram alguns a caracterizar a situação contemporânea de "crise" do direito ao asilo.

Migrações e deslocamentos forçados aumentaram, intensificaram-se a partir dos $90^{7}$ e foram caracterizados particularmente

S. Ogata, Los Retos de la Protección de los Refugiados (Declaração no Ministério das Relações Exteriores do Mexico, 29.07.1999), Cidade do México, ACNUR, 1999, p. 11 (circulação interna). - Foi recentemente colocado que sistemas de aviso prévio (originalmente imaginado e usado no campo do Direito Internacional dos Refugiados) descobriu algumas fraquezas, usados para coagir pessoas sob stress a não migrar; S. Schmeidl, "The Early Warning of Forced Migration: State or Human Security?", in Refugees and Forced Displacement - International Security, Human Vulnerability, and the State (eds. E. Newman and J. van Selm), Tokyo, Universidade das Nações Unidas, 2003, pp. 140, 145 e 149-151. Da perspectiva da sociedade civil como um todo, o argumento foi proposto em favor de assegurar completa e efetiva cidadania a migrantes que estão de acordo com a lei; M. Frost, "Thinking Ethically about Refugees: A Case for the Transformation of Global Governance", in ibid., pp. 128-129.

6 Pela necessidade de "reavaliar" o que é humano e humanitário atualmente, cf. J.A. Carrillo Salcedo, "El Derecho Internacional ante un Nuevo Siglo", 48 Boletim da Faculdade de Direito da Universidade de Coimbra (1999-2000) p. 257, and cf. p. 260.

7 M. Lengellé-Tardy, L'esclavge moderne, Paris, PUF, 1999, pp. 26, e 116, cf. pp. 97-98. pelas disparidades das condições de vida entre o país de origem e aquele de destino dos migrantes. As causas são múltiplas, a saber: colapso econômico e desemprego, colapso dos serviços públicos (educação, saúde, entre outros), desastres naturais, conflitos armados gerando fluxos de refugiados e deslocados internos, repressão e perseguição, violação sistemática dos direitos humanos, rivalidades étnicas e xenofobia, e violência de distintas formas ${ }^{8}$. Em anos recentes, a chamada "flexibilidade" das relações de trabalho, entre as quais se insere a "globalização" da economia, também gerou mobilidade, acompanhada de insegurança pessoal e um crescente medo do desemprego 9 .

Migrações e deslocamentos forçados, com o conseqüiente desarraigamento, causam fortes traumas. Testemunhas de migrações relatam o sofrimento do abandono do lar, às vezes com a separação da família ou

8 N. Van Hear, New Diasporas - The Mass Exodus, Dispersal and Regrouping of Migrant Communities, London, UCL Press, 1998, pp. 19-20, 29, 109-110, 141, 143 and 151; F.M. Deng, Protecting the Dispossessed - A Challenge for the International Community, Washington D.C., Brookings Institution, 1993, pp. 3-20. Ecf., também, e.g., H. Domenach and M. Picouet, Les migrations, Paris, PUF, 1995, pp. 42-126.

9 N. Van Hear, op. cit. supra n. (10), pp. 251-252. Assim como foi ressaltado, "a ambiguidade da mifração é o resultado do sucesso do capitalismo em adotar a pentração das mercadorias em sociedades periféricas e minar a capacidade dessas sociedades em se auto-sustentar. Na medida que esse 'sucesso' irá continuar, migrantes também irão continuar a emergir nas periferias do capitalismo"; ibid., p. 260. Cf. also R. Bergalli (coord.), Flujos Migratorios y Su (Des)control, Barcelona, OSPDH/ Anthropos Edit., 2006, pp. 138, 152 and 244-248. -Para um estudo de caso, cf., e.g., M. Greenwood Arroyo and R. Ruiz Oporta, Migrantes Irregulares, Estrategias de Sobrevivencia y Derechos Humanos: Un Estudio de Casos, São José da Costa Rica, IIHR, 1995, pp. 9-159. 
desagregação, a perda da propriedade e pertences pessoais, a arbitrariedade e humilhação por parte das autoridades de fronteiras e agentes de segurança, gerando um sentimento permanente de injustiça ${ }^{10}$. Como Simone Weil alertou em meados do século XX, "possuir raízes é, talvez, a mais importante e menos reconhecida necessidade da alma humana. É uma das mais difíceis de se definiri" ${ }^{11}$.

Ao mesmo tempo e na mesma linha de pensamento, Hannah Arendt alertou sobre os sofrimentos dos desabrigados (a perda da casa e da familiaridade da vida diária, a perda da profissão e do sentimento de ser útil para os outros, a perda da língua materna como possibilidade espontânea de expressar sentimentos), assim como a ilusão de tentar esquecer o passado ${ }^{12}$. Na mesma linha de raciocínio, no seu livro Le retour du tragique (1967), J.-M. Domenach observou que uma pessoa não pode negar as raízes do próprio espírito humano, uma vez que a aquisição do conhecimento por parte de cada indivíduo - e conseqüientemente sua forma de entender o mundo - sendo condicionada por fatores

\footnotetext{
${ }^{10}$ Ibid., p. 152.
}

11 Simone Weil, The Need for Roots, London/N.Y., Routledge, 1952 (reimpressa 1995), p. 41. - Sobre o drama contemporâneo do desarraigamento, cf. A.A. Cançado Trindade, "Reflexiones sobre el Desarraigo como Problema de Derechos Humanos Frente a la Conciencia Jurídica Universal", in La Nueva Dimensión de las Necesidades de Protección del Ser Humano en el Inicio del Siglo XXI (eds. A.A. Cançado Trindade and J. Ruiz de Santiago), 4a. rev. ed., São José da Costa Rica, ACNUR, 2006, pp. 33-92.

12 Hannah Arendt, La tradition cachée, Paris, Ch. Bourgois Ed., 1987 (orig. ed. 1946), pp. 58-59 and 125127. E cf., também sobre o assunto, e.g., C. BordesBenayoun and D. Schnapper, Diasporas et nations, Paris, O. Jacob Ed., 2006, pp. 7, 11-12, 45-46, 63-65, 68-69, 129 and 216-219. como o lugar de nascimento, a língua materna, os cultos, a família e a cultura ${ }^{13}$.

No seu livro Le temps des déracinés (2003), Elie Wiesel ${ }^{14}$ comentou que os antigos refugiados, ainda que já estabelecidos em um novo país, continuavam, de alguma forma, refugiados pelo resto de suas vidas; eles escapam de um lugar para outro em virtude de garantir sua própria proteção, com tudo parecendo provisório e sem se sentir em casa onde quer que estejam. Eles sempre permanecem lembrando de seu lugar de origem $^{15}$, cultivando suas memórias como meio de defender-se da adversa condição de desarraigamento. No entanto, a "celebração da memória" possui suas limitações, pois os refugiados estão privados de horizonte, e do senso de pertencer a algum lugar ${ }^{16}$. Sempre precisam da ajuda de outros. O drama dessas vítimas parece ser esquecido e negligenciado com o passar do tempo, e os desarraigados terminam por ter que aprender a viver com a lenta e inevitável diminuição de, até mesmo, suas próprias memórias ${ }^{17}$.

Em minha opinião, em separado, no caso da Comunidade Moiwana versus Suriname perante a Corte Interamericana de Direitos Humanos (Julgamento de 15/06/2005),

13 J.-M. Domenach, Le retour du tragique, Paris, Éd. Seuil, 1967, p. 285.

${ }^{14}$ Prêmio Nobel em 1986, ele mesmo uma vítima do drama do desarraigamento.

15 E. Wiesel, O Tempo dos Desenraizados (Le temps des déracinés, 2003), Rio de Janeiro, Edit. Record, 2004, pp. 18-19.

${ }^{16}$ Ibid., pp. 21, 32, 181 and 197.

${ }^{17}$ Ibid., pp. 212, 235, 266 and 278. Sobre suas preocupações com a necessidade de preservar a memória, cf. também Elie Wiesel, L'oublié, Paris, Éd. Seuil, 1989, pp. 29, 63, 74-77, 109, 269, 278 e 336. 
debrucei-me precisamente sobre a projeção do sofrimento humano no tempo dos migrantes daquela comunidade (da qual alguns fugiram para a Guiana Francesa) os quais sobreviveram a um massacre (perpetrado em 29/11/1986, na vila N'djuka Maroon de Moiwana, no Suriname). Na oportunidade caracterizei o sofrimento acarretado como

sofrimento espiritual. Na sua cultura, eles permanecem atormentados pelas circunstâncias das mortes violentas de seus entes queridos, e pelo fato de que os que partiram não tiveram a oportunidade de oferecer um enterro apropriado a seus entes queridos. Essa privação, gerando sofrimento espiritual, permaneceu por quase vinte anos, a partir da perpetração do massacre de 1986, clamando pela responsabilidade do Estado até este momento. Os N'djukas não esqueceram dos seus mortos (par. 29).

Somente com o mencionado Julgamento de 2005, quase duas décadas depois, eles ao menos, encontraram reparo, com o reconhecimento jurídico do seu sofrimento e as reparações ordenadas. Entre as reparações, encontra-se a garantia, pelo Estado, do retorno voluntário e seguro dos $\mathrm{N}^{\prime}$ djukas para sua terra natal ${ }^{18}$. Não foi a primeira vez que eu comentei a questão da projeção do sofrimento humano no tempo e a crescente tragédia do dessarraigamento; anteriormente, fiz o mesmo no meu Parecer Concordante (pars. 1-25) na Ordem da Corte de Medidas Provisórias de Proteção (de 18/08/2000) no caso dos Haitianos e os

${ }_{18}$ Para o texto completo do meu Parecer Separado no caso da Comunidade Moiwana versus Suriname, cf. A.A. Cançado Trindade, Derecho Internacional de los Derechos Humanos - Esencia y Trascendencia (Votos en la Corte Interamericana de Derechos Humanos, 1991-2006), Mexico, Edit. Porrúa/Universidad Iberoamericana, 2007, pp. 539-567.
Dominicanos de Origem Haitiana na República Dominicana, assim como no meu Parecer Separado (pars. 10-14) no caso Bámaca Velásquez versus Guatemala (Reparações, Julgamento de 22/02/2002) ${ }^{19}$, e retomei o ponto em questão no mais recente caso da Comunidade Moiwana ${ }^{20}$.

De fato, a projeção do sofrimento humano no tempo (sua dimensão temporal) foi propriamente reconhecida, e.g., no documento final da Conferência Mundial das Nações Unidas contra Racismo, Discriminação Racial, Xenofobia e Intolerâncias Relacionadas (Durban, 2001), sua adotada Declaração e Plano de Ação. A respeito do tema, começou por afirmar que:

nós estamos conscientes do fato que a história da humanidade é repleta de grandes atrocidades como resultado da violação aos direitos humanos, e acreditamos que lições podem ser aprendidas ao lembrarmos da história para prevenir tragédias futuras (par. 57).

O documento, então, enfatizou a "importância e a necessidade de ensinar sobre os fatos e a verdade da história da humanidade", com o objetivo de "atingir um conhecimento objetivo e compreensivo das tragédias do passado" (par. 98). Nessa linha de pensamento, o documento final de Durban reconheceu e

${ }^{19}$ Para o texto complete dos mencionados Parecerces Concordante e Separado, cf. ibid., pp. 876-883 and 321330 , respectivamente.

${ }^{20}$ É significativo que, em seu Julgamento sobre o caso Comunidade Moiwana versus Suriname, a Corte Inter-Americana, nas bases da Convenção Americana e à luz do princípio jura novit curia, devotou uma sessão inteira do presente Julgamento a deslocamentos forçados - uma malaise dos nossos tempos - e estabeleceu uma violação do Artigo 22 da Convenção Inter-Americana (na liberdade de movimento e residência) pelo Estado respondente em combinação com o dever geral do Artigo 1(1) da Convenção (pars. 101-119). 
lamentou profundamente o "sofrimento humano massivo" e o "drama" de milhões de seres humanos causado por atrocidades do passado; o documento, então, chamou os Estados a "honrar a memória das vítimas de tragédias passadas" e afirmou que, independentemente dos lugares e do tempo em que tais tragédias tinham acontecido, "elas devem ser condenadas e sua recorrência evitada" (par. 99).

O documento final da Conferência de Durban atribuiu particular importância para relembrar os crimes e abusos do passado, em termos enfáticos:

nós enfatizamos que relembrar os crimes e erros do passado, independentemente dos lugares e do tempo em que ocorreram, inequivocamente condenando as tragédias racistas e dizendo a verdade sobre a história, são elementos essenciais para a reconciliação internacional e para a criação de sociedades baseadas na justiça, igualdade e solidariedade (par. 106).

Por fim, foi reconhecido que "injustiças históricas" contribuíram, sem dúvidas, para a pobreza, marginalização, exclusão social, instabilidade e insegurança, afetando diversas pessoas em distintas partes do mundo (par. 158).

Tal qual diz Jaime Ruiz de Santiago, o drama dos refugiados e migrantes desarraigados em geral - somente pode ser abordado apropriadamente por meio de um espírito de solidariedade internacional em relação às vítimas ${ }^{21}$. Definitivamente, somente

${ }^{21}$ Jaime Ruiz de Santiago, "Derechos Humanos, Migraciones y Refugiados: Desafios en los Inicios del Nuevo Milenio", in III Encuentro de Movilidad Humana: Migrante y Refugiado - Memoria (Setembro 2000), São José da Costa Rica, UNHCR/IIHR, 2001, pp. 37-72; e cf. Jaime Ruiz de Santiago, Migraciones Forzadas - Derecho a firme determinação da reconstrução da comunidade internacional ${ }^{22}$ nas bases da solidariedade humana ${ }^{23}$ pode levar à mitigação ou ao alívio de alguns sofrimentos dos desarraigados (sejam refugiados, deslocados internos ou migrantes).

\section{PRINCÍPIOS BÁSICOS SOBRE DESLOCADOS INTERNOS}

Nas últimas três décadas, o problema dos deslocados internos desafiou as bases das normas da proteção internacional, demandando um aggiornamento dessas normas e novas respostas a uma situação, originalmente, não prevista ao tempo da elaboração dos instrumentos internacionais relevantes. Esses instrumentos revelaram-se insuficientes, tal como, por exemplo, a original falta de normas expressamente dirigidas a superar a alegada não-aplicabilidade das normas de proteção a atores não-estatais, a não-tipificação de deslocados internos de acordo com normas originais de proteção e a possibilidade de restrições ou degradações minando a proteção em momentos críticos. Essas insuficiências

Internacional y Doctrina Social de la Iglesia, México, Instituto Mexicano de Doctrina Social Cristiana, 2004, pp. 9-82.

${ }^{22}$ Cf., e.g., A.A. Cançado Trindade, "Human Development and Human Rights in the International Agenda of the XXIst Century", in Human Development and Human Rights Forum (Agosto 2000), São José da Costa Rica, UNDP, 2001, pp. 23-38; cf. também, e.g., L. Lippolis, Dai Diritti dell'Uomo ai Diritti dell'Umanità, Milano, Giuffrè, 2002, pp. 21-23 e 154-155.

${ }^{23}$ Quanto ao significado deste último, cf., em geral, L. de Sebastián, La Solidaridad, Barcelona, Ed. Ariel, 1996, pp. 12-196; J. de Lucas, El Concepto de Solidaridad, 2nd. ed., Mexico, Fontamara, 1998, pp. 13-109; entre outros. 
resultaram em iniciativas de proteção tanto em nível global (Nações Unidas) quanto em nível regional (América Latina) -, iniciativas que buscaram uma estrutura conceitual que permite o desenvolvimento de respostas, em nível operativo, para as novas necessidades da proteção. É, portanto, apropriado que nos movamos para uma breve revisão dessas iniciativas.

\section{Nível Global (Nações Unidas)}

Em nível global (ONU), uma década atrás, no primeiro trimestre de 1998, a antiga Comissão das Nações Unidas para Direitos Humanos, tendo em mente os relatórios feitos pelo Representante do Secretário Geral para Deslocados Internos (F. M. Deng) ${ }^{24}$, ao menos adotou os chamados Princípios Orientadores sobre Deslocados Internos ${ }^{25}$, apesar da persistência do problema ao longo das últimas duas décadas. O propósito básico dos Princípios Orientadores era reforçar e fortalecer os já existentes meios de proteção; nesse sentido, os princípios propostos servem tanto para governantes quanto para grupos insurgentes, em todos os estágios do deslocamento. O princípio básico de nãodiscriminação ocupa uma posição central no supracitado documento de $1998^{26}$, que se

${ }^{24}$ Esses relatórios afirmaram a importância da prevenção (e.g., reforçando a proteção dos direitos à vida e à integridade pessoal, assim como o direito à propriedade da terra e de bens); cf. F.M. Deng, Internally Displaced Persons (Relatório Interino), N.Y., RPG/DHA, 1994, p. 21; e cf. U.N., doc. E/CN.4/1995/50/Add.1, de 03.10 .1994$, p. 34.

${ }^{25}$ Para comentários, cf. W. Kälin, Guiding Principles on Internal Displacement -Annotations, Washington D.C., ASIL/Brookings Institution, 2000, pp. 1-276.

\footnotetext{
${ }^{26}$ Princípios 1(1), 4(1), 22, 24(1).
}

certifica em destinar, aos deslocados internos, os mesmos direitos desfrutados pelas outras pessoas no país ${ }^{27}$.

Os mencionados Princípios Orientadores de 1998 determinam que o deslocamento não pode dar-se de modo que viole os direitos à vida, à dignidade, à liberdade e à segurança das pessoas afetadas ${ }^{28}$; eles também afirmam outros direitos, como o direito ao respeito pela vida familiar, o direito a um adequado padrão de vida, o direito à igualdade perante a lei, o direito à educação ${ }^{29}$. A idéia básica por trás de todo o documento ${ }^{30}$ está no sentido que os deslocados internos não perdem seus direitos intrínsecos como resultado do deslocamento, e podem invocar as pertinentes normas de proteção internacional (tanto do Direito Internacional Humanitário quanto dos Direitos Humanos Internacionais) para salvaguardar seus direitos.

Em uma significante resolução adotada em 1994, a então Comissão de Direitos Humanos das Nações Unidas, tendo em mente, em particular, os casos de deslocados internos, recordou as relevantes normas, em todo o conjunto, do Direito Internacional dos Direitos Humanos e do Direito Internacional Humanitário, assim como do Direito Internacional dos Refugiados, pertinentes para o problema em questão ${ }^{31}$. A Resolução

27 Afirma, mais adiante, a proibição do "deslocamento arbitrário", (Princípio 6).

28 Princípio 8 e seguintes.

29 Princípios 17, 18, 20 e 23, respectivamente.

30 Para uma "abordagem ampla" sobre os deslocados incluindo também o problema das migrações forçadas como um todo, tendo em mente os Princípios das Nações Unidas sobre Deslocados Internos, cf. C. Phuong, The International Protection of Internally Displaced Persons, Cambridge, University Press, 2004, pp. 54-55 and 237.

${ }^{31} 2$. $^{\circ}$ parágrafo preambular. 
1994/68, adotada pela Comissão em 09/03/1994, recordou ainda a Declaração e Plano de Ação de Viena (adotada pela II Conferência Mundial sobre Direitos Humanos), que chamava por uma "compreensiva abordagem da comunidade internacional no que diz respeito aos refugiados e aos deslocados internos" 32 .

O documento ainda sublinhou a "dimensão humanitária" do "problema dos deslocados internos e as responsabilidades que esse problema traz para os Estados e para a comunidade internacional" ${ }^{33}$. O documento ainda chamou atenção para a "necessidade de abordar as causas fundamentais que dão origem aos deslocamentos internos ${ }^{34}$ ", assim como "continuar a aumentar o nível de consciência sobre o drama dos deslocados internos" ${ }^{35}$. Mais de uma década depois, essas considerações continuam válidas, atualmente, para os migrantes (cf. infra), que adicionam uma maior dimensão para o sofrimento dos desarraigados em geral no nosso - impropriamente chamado - mundo "globalizado".

\section{Nível Regional}

No continente americano, a Declaração de Cartagena sobre Refugiados de 1984, a Declaração de São José sobre Refugiados e Pessoas Deslocadas, a Declaração e o Plano de Ação do México de 2004 para Fortalecer a Proteção Internacional dos Refugiados na

\footnotetext{
32 7. ${ }^{\circ}$ parágrafo preambular.

${ }^{33} 5^{\circ}$ parágrafo preambular.

$3412 .{ }^{\circ}$ parágrafo preambular.

35 Parágrafo 3 (ênfase adicional).
}

América Latina são, cada um deles, produtos de um determinado momento histórico. O primeiro, a Declaração de Cartagena, foi motivado por necessidades urgentes que, por sua vez, foram geradas por uma crise de grandes proporções; na extensão em que essa crise estava sendo resolvida, em parte devido a essa Declaração, seu legado começou a ser projetado a outras regiões e sub-regiões do continente americano.

A segunda declaração foi adotada entre uma distinta crise, mais difusa, marcada pela deterioração das condições socioeconômicas de grandes segmentos da população em distintas regiões. Em suma, Cartagena e São José foram produtos de seu tempo. O aggiornamento do Colóquio de São José deram, igualmente, uma ênfase especial na identificação das necessidades de proteção do ser humano em quaisquer circunstâncias ${ }^{36}$. Não restou, então, lugar para vacatio legis ${ }^{37}$. A Declaração de São José de 1994 deu ênfase especial não somente a todo o problema dos deslocados internos, mas também, de forma mais abrangente, aos desafios apresentados pelas novas situações de desarraigamento na América Latina e no Caribe, incluindo as migrações forçadas originadas por causas distintas daquelas previstas pela Declaração de Cartagena.

A Declaração de 1994 reconheceu que a violação de Direitos Humanos é uma das

${ }^{36}$ Ao invés de categorizações subjetivas de pessoas (de acordo com as razões que os levaram a abandonar suas casas), próprias do passado, hoje em dia o critério objetivo da necessidade de proteção foi adotado, abrangendo, pois, um número considerável de pessoas (incluindo deslocados internos) tão vulneráveis quanto os refugiados, ou ainda mais que estes.

${ }^{37}$ Ibid., pp. 14-15. 
causas de deslocamentos forçados e que, portanto, a proteção desses direitos e o fortalecimento do sistema democrático constitui a melhor medida para a procura de soluções duráveis, assim como para a prevenção de conflitos, o êxodo de refugiados e graves crises humanitárias ${ }^{38}$. Recentemente, ao fim de consultas, com uma grande participação pública, feitas por iniciativa do ACNUR, a Declaração e o Plano de Ação do México para Fortalecer a Proteção Internacional dos Refugiados na América Latina foi $\operatorname{adotada}^{39}$, na ocasião do vigésimo aniversário da Declaração de Cartagena (supra). Pela primeira vez no presente processo, um documento desse porte foi acompanhado por um Plano de Ação. Isso pode ser explicado pelo agravamento da crise humanitária na região, particularmente na sub-região dos Andes.

Como o Rapporteur do Comitê de "Experts" Legais do ACNUR observou, em sua apresentação do relatório final para o Colóquio do México, na primeira sessão plenária, em 15 de Novembro de 2004, embora os momentos da Declaração de Cartagena de 1984 e a Declaração de são José de 1994 sejam distintos, suas conquistas "cumulam e constituem, hoje, um patrimônio jurídico" de todas as pessoas da região, revelando as novas tendências do desenvolvimento das salvaguardas internacionais dos diretos da pessoa humana frente às necessidades de proteção, e projetam os mesmos no futuro ${ }^{40}$. Assim,

${ }^{38}$ Ibid., pp. 431-432.

${ }^{39} \mathrm{Cf}$. Texto reproducido in: UNHCR, Memoria del Vigésimo Aniversario de la Declaración de Cartagena sobre los Refugiados (1984-2004), Mexico City/São José da Costa Rica, UNHCR, 2005, pp. 385-398.

${ }^{40}$ Cf. "Presentación por el Dr. A.A. Cançado Trindade del Comité de Consultores Jurídicos del ACNUR" (Cidade a Declaração de Cartagena enfrentou o grande drama humano dos conflitos armados na América Central; no entanto, mais adiante, previu o agravamento do problema dos deslocados internos. A Declaração de São José, por sua vez, lidou mais profundamente com a questão da proteção de, além dos refugiados, também dos deslocados internos, mas previu também o agravamento do problema de fluxos migratórios forçados. Desde que anacrônicas categorizações foram superadas, próprias de uma maneira de pensar sobre um passado que não mais existe, e foi reconhecida as convergências entre os três regimes de proteção internacional dos diretos da pessoa humana, ou seja, o Direito Internacional dos Refugiados, o Direito Internacional Humanitário e o Direito Internacional dos Direitos Humanos. Essas convergências - nos níveis normativo, hermenêutico e operativo - foram reafirmados em todos os encontros preparatórios para o presente Colóquio Comemorativo da Cidade do México, e têm repercussões atualmente em outras partes do mundo, conformando a maior e mais lúcida doutrina legal no assunto ${ }^{41}$.

Essas convergências ${ }^{42}$ foram, não surpreendentemente, refletidas, de modo mais

do México, 15.11.2004), in UNHCR, Memoria del Vigésimo Aniversario de la Declaración de Cartagena..., op. cit. supra n. (41), pp. 368-369.

${ }^{41}$ Ibid., p. 369.

${ }^{42}$ Cf. A.A. Cançado Trindade, "Derecho Internacional de los Derechos Humanos, Derecho Internacional de los Refugiados y Derecho Internacional Humanitario: Aproximaciones y Convergencias", in 10 Años de la Declaración de Cartagena sobre Refugiados - Memoria del Coloquio Internacional (São José da Costa Rica, Dec. 1994), São José da Costa Rica, IIDH/UNHCR, 1995, pp. 77-168; A.A. Cançado Trindade, "Aproximaciones y Convergencias Revisitadas: Diez Años de Interacción entre el Derecho Internacional de los Derechos Humanos, el Derecho Internacional de los Refugiados, y el Derecho Internacional Humanitario (De Cartagena/1984 a San José/1994 y México/2004)", in Memoria del Vigésimo Aniversario de la Declaración de Cartagena sobre Refugiados (1984-2004), São José da Costa Rica, UNHCR, 2005, pp. 139-191. 
enfático, no Plano de Ação e na Declaração do México de 2004 para Fortalecer a Proteção Internacional dos Refugiados na América Latina. Assim, como o Rapporteur do Comitê de "Experts" Legais do ACNUR finalmente observou no Colóquio do México de 2004, “não há lugar para a vacatio legis, não há vácuo legal, e todas (...) pessoas estão sob a proteção da lei, em todas e quaisquer circunstâncias (também em face de medidas de segurança)" ${ }^{43}$.

Esses desenvolvimentos são significativos por abordar a questão de migrações internas forçadas, e a garantia de um retorno voluntário e seguro. Ainda, o problema de migrações forçadas tem uma maior dimensão, e apresenta-se como um considerável desafio à comunidade internacional como um todo. Somente durante os anos noventa o problema de fluxos de migrações forçadas foi identificado e começou a ser lidado como um grave problema, de modo sistemático.

\section{PRINCÍPIOS BÁSICOS EM MIGRAÇÕES}

Até então, enquanto a população de refugiados superava os 18 milhões de pessoas, e a população de deslocados internos superava os 7 milhões (totalizando 25 milhões de pessoas) ${ }^{44}$, os migrantes, em busca de melhores condições de vida e de trabalho, por sua vez, totalizavam 80 milhões de pessoas ao fim do século $\mathrm{XX}^{45}$, e - de

${ }^{43}$ Ibid., p. 369.

${ }^{44}$ F.M. Deng, Protecting the Dispossessed..., op. cit. supra n. (10), pp. 1 and 133.

45 A.A. Cançado Trindade, "Prefácio" para: V.O. Batista, União Européia: Livre Circulação de Pessoas e Direito de Asilo, Belo Horizonte/Brasil, Edit. Del Rey, 1998, p. 9. acordo com dados recentes da Organização Internacional para Migrações (OIM) - atinge hoje em torno de 100 a 120 milhões de migrantes em todo o mundo ${ }^{46}$. Ainda, o sofrimento dos migrantes é conhecido por longos anos ${ }^{47}$.

As causas de migrações forçadas não são fundamentalmente distintas daquelas dos deslocamentos forçados populacionais: desastres naturais, pobreza crônica, conflitos armados, violência generalizada, violação sistemática dos direitos humanos ${ }^{48}$. Na antiga Comissão das Nações Unidas sobre Direitos Humanos, foi apontado que, no meio dos anos noventa, os desafios desse novo fenômeno deviam ser examinados no contexto da realidade pós-Guerra Fria, de caráter étnico e religioso, reprimidos no passado, mas que emergiu em anos recentes, precisamente com o fim da Guerra Fria ${ }^{49}$.

46 Jaime Ruiz de Santiago, El Problema de las Migraciones Forzosas en Nuestro Tiempo, Mexico, IMDSC, 2003, p. 10; e cf. projeções in: S. Hune and J. Niessen, "Ratifying the U.N. Migrant Workers Convention: Current Difficulties and Prospects", 12 Netherlands Quarterly of Human Rights (1994) p. 393.

${ }^{47}$ Sobre as adversidades sofridas pelos (estrangeiros) trabalhadores migrantes (e.g., discriminação com base na raça, nacionalidade, entre outros), cf., inter alia, S. Castles and G. Kosack, Los Trabajadores Inmigrantes y la Estructura de Clases en Europa Occidental, México, FCE, 1984, pp. 11-565.

${ }^{48}$ Cit. in F.M. Deng, Protecting the Dispossessed..., op. cit. supra n. (10), p. 3.

${ }^{49}$ Ibid., p. 4. - Avisaram-nos que, em relação aos migrantes, o Estado acolhedor está sempre disposto a exercer seu poder, e as distintas atitudes dos Países Europeus Ocidentais, de assimilação ou segregação dos migrantes, têm tido implicações conflituosas; E. Todd, El Destino de los Inmigrantes - Asimilación y Segregación en las Democracias Occidentales (transl. of Le destin des immigrés - Assimilation et ségrégation dans les démocraties occidentales), Barcelona, Tusquet Edit., 1996, pp. 147, 347, 351 e 353. O Drama dos 
Ao que foi exposto é adicionado o crescimento da pobreza crônica ${ }^{50}$. Para enfrentar esse novo fenômeno de migrações forçadas, a Assembléia Geral das Nações Unidas aprovou, no dia 18/12/1990, a Convenção Internacional sobre a Proteção dos Direitos de Todos os Trabalhadores Migrantes e suas Famílias. Essa importante Convenção, que finalmente entrou em vigor em 01/07/2003, tem, no entanto, recebido poucas ratificações - até o início de Abril de 2007 , somente 36 - e não tem sido ainda suficientemente permeada pela doutrina contemporânea, apesar de seu considerável valor. A Convenção de 1990 estabeleceu o Comitê para a Proteção dos Direitos de Todos os Trabalhadores Migrantes e suas Famílias como seu órgão supervisor (Artigo 72), encarregado da análise de relatórios de Estados (Artigos 73-74), assim como comunicações e queixas inter-estatais e de indivíduos (Artigos 76-77).

No meio dos anos noventa, o então Centro das Nações Unidas para Direitos Humanos identificou, como causa dos fluxos contemporâneos de migrações forçadas, a extrema pobreza (abaixo dos níveis de subsistência), procura por trabalho, conflitos armados, insegurança pessoal ou perseguição em virtude de discriminação (tendo como base a raça, origem étnica, cor, religião, língua ou opiniões políticas) ${ }^{51}$. A idéia básica

Migrantes - seu anseio por raízes e sua própria identidade cultutal - têm, assim, persistido.

${ }^{50}$ Que, de acordo com dados do Programa das Nações Unidas para o Desenvolvimento (UNPD), somente na América Latina, hoje, mais de 270 milhões de pessoas são vítimas (comparados com 250 milhões dos anos oitenta), os quais podem chegar perto dos 300 milhões.

51 U.N./Centro para Direitos Humanos, Los Derechos de los Trabajadores Migratorios (Foll. Inf. n. 24), Genebra, U.N., 1996, p. 4. por trás da Convenção Internacional sobre a Proteção dos Direitos de Todos os Trabalhadores Migrantes e suas Famílias é que todos os trabalhadores migrantes - assim qualificados na Convenção - devem desfrutar de seus direitos humanos independentemente de sua situação legal ${ }^{52}$.

Dessa forma, a posição central é ocupada, também nesse contexto, pelo princípio de não-discriminação (como estipulados no Artigo 7). Sem maiores surpresas, uma lista de direitos segue uma necessária visão holística ou integral dos direitos humanos (compreendendo direitos civis, políticos, econômicos, sociais e culturais). AConvenção tomou em consideração os padrões de trabalho internacionais (derivado da experiência da OIT - cf. infra), assim como aqueles das Convenções das Nações Unidas contra a discriminação ${ }^{53}$.

Os direitos de proteção são enunciados em três das nove partes que conformam a Convenção: Parte III (Artigos 8-35) lista os direitos humanos de todos os migrantes trabalhadores e os membros de suas famílias (incluindo aqueles sem documentos); Parte IV (Artigos 36-56) cobre outros direitos de trabalhadores migrantes e membros de suas famílias "que possuem documentos ou estejam em uma situação regular"; e Parte V (Artigos 57-63) contém disposições aplicáveis a "categorias particulares" de trabalhadores migrantes e membros de suas famílias ${ }^{54}$.

\footnotetext{
${ }^{52}$ Ibid., pp. 15-16.

${ }^{53}$ Cf. ibid., p. 16.

${ }^{54}$ Quais sejam, trabalhadores de fronteiras,
} trabalhadores temporários, trabalhadores itinerantes, trabalhadores contratados por projetos, com emprego fixo, por conta própria - nos termos das definições do Artigo 2(2) da Convenção de 1990. O Artigo 2(1) define 
O princípio básico de não-discriminação, que possui uma longa história e ao qual muita importância tem sido atribuída no processo de elaboração da Declaração Universal dos Direitos Humanos de $1948^{55}$, e que subseqüientemente foi o principal objetivo de duas importantes Convenções das Nações Unidas (CERD, 1966, e CEDAW, 1979) - as quais cobrem somente certos aspectos de tal princípio - tem sido, somente em anos recentes, utilizada de modo que melhor explora seu potencial de aplicação, tal como nas Opiniões Consultivas ns. 16 e 18 da Corte Inter-Americana de Direitos Humanos, no caso sobre $O$ Direito à Informação sobre Assistência Consular no contexto das Garantias do Devido Processo Legal (1999), e no caso sobre A Condição Jurídica e os Direitos dos Migrantes sem Documentos (2003), respectivamente.

Como, na visão dos Estados, não há "direito humano para imigrar", o controle de entrada de migrantes está sujeito a seus respectivos critérios "soberanos", também para "proteger" seus mercados internos ${ }^{56}$. Ao invés de conceber e aplicar verdadeiras políticas populacionais, tendo em mente os direitos humanos, a maioria dos Estados tem exercido a estrita função política de "proteger" suas fronteiras e controlar fluxos migratórios,

"trabalhador migrante" como "uma pessoa que está para ser contratada, está contratada ou foi contratada para uma atividade remunerada em um Estado do qual ela não é cidadã".

${ }^{55} \mathrm{Cf}$. A. Eide et alii, The Universal Declaration of Human Rights - A Commentary, Oslo, Scandinavian University Press, 1992, p. 6.

56 M. Weiner, "Ethics, National Sovereignty and the Control of Immigration", 30 International Migration Review (1996) pp. 171-195. e sancionado os chamados migrantes "ilegais". Toda a questão tem sido indevidamente e desnecessariamente "criminalizada".

Dessa forma, não é surpreendente que inconsistências e arbitrariedades decorram daí em diante. Estas se manifestam em "regimes democráticos" cuja administração da justiça, não obstante, ainda não conseguiu se livrar de antigos preconceitos contra os imigrantes, principalmente quando esses são pobres e desprovidos de documentos. Os programas de "modernização" da justiça, com financiamento internacional, não se aprofundam nesse aspecto, uma vez que sua maior motivação é assegurar a segurança de investimentos (bens e capitais).

Isso fornece uma reveladora imagem da (reduzida) dimensão que autoridades públicas têm conferido aos seres humanos no começo do século XXI, colocada em uma escala inferior àquela atribuída a bens e capitais - a despeito de todas as lutas do passado e de todo o sofrimento de antigas gerações. A área na qual as maiores incongruências aparecem manifesta-se, nos dias de hoje, na forma daquela relativa às garantias do Devido Processo Legal.

Ainda, a reação da Lei tem se tornado pontual e manifestando-se, atualmente, como demonstrado, por exemplo, pelas pioneiras Opiniões Consultivas ns. 16 e 18 da Corte Interamericana de Direitos Humanos, no caso sobre $O$ Direito à Informação sobre Assistência Consular no contexto das Garantias do Devido Processo Legal (1999), e no caso sobre A Condição Jurídica e os Direitos dos Migrantes sem Documentos (2003), respectivamente. A Opinião Consultiva n. 16 colocou o Direito de notificação consular, como estipulado pelo Artigo 36(1) (b) da 
Convenção de Viena de 1963 sobre Relações Consulares, no universo conceitual da Legislação do Direito Internacional dos Direitos Humanos. Isso tem, sem dúvidas, conferido uma dimensão de direitos humanos a alguns postulados do clássico direito consular, como apontei em meu Parecer Concordante (pars. 1-35) $)^{57}$ na mencionada $16^{\mathrm{a}}$ Opinião Consultiva da Corte.

Desde que foi emitida pela Corte, a $16^{\mathrm{a}}$ Opinião Consultiva, apesar de inspirar a jurisprudência internacional in statu nascendi, tem tido um considerável impacto na prática internacional no continente Americano (mais particularmente na América Latina ${ }^{58}$ ). Ainda, há grande necessidade de uma maior e genuína cooperação internacional para assegurar assistência e proteção a todos os migrantes e aos membros de suas famílias. Normas legais não podem ser efetivas sem valores correspondentes e subjacentes e, no presente campo, a aplicação das relevantes normas requer, sobretudo, uma fundamental mudança de mentalidade.

Em relação ao presente assunto, as normas já existem, mas o devido reconhecimento dos valores, ao que parece, ainda está ausente, assim como a referida nova mentalidade. Não é meramente casual que a Convenção Internacional sobre a Proteção de Todos os Migrantes Trabalhadores

57 Cf. texto in: A.A. Cançado Trindade, Derecho Internacional de los Derechos Humanos - Esencia y Trascendencia (Votos en la Corte Interamericana de Derechos Humanos, 1991-2006), Mexico, Edit. Porrúa/ Universidad Iberoamericana, 2007, pp. 15-27.

${ }^{58}$ Cf. A.A. Cançado Trindade, "The Humanization of Consular Law: The Impact of Advisory Opinion n. 16 (1999) of the Inter-American of Human Rights on International Case-Law and Practice", 4 Chinese Journal of International Law (2007) pp. 1-16. e os Membros de Suas Famílias, apesar de ter entrado em vigor em 01/07/2003, como apontado anteriormente, não tenha sido ratificada por muitos Estados até agora ${ }^{59}$ (cf. supra). Apesar da identidade dos princípios básicos e da legislação aplicável em distintas situações, a proteção dos migrantes requer, não obstante, uma ênfase especial em um e outro aspecto em particular. O ponto inicial, ao que tudo indica, refere-se ao reconhecimento que todo migrante tem o direito de desfrutar de todos os direitos humanos fundamentais, assim como dos direitos derivados dos empregos que ocupavam no passado, independentemente de sua situação jurídica (seja ela regular ou não).

Aqui, mais uma vez, uma visão holística ou integral de todos os direitos humanos (civis, políticos, econômicos, sociais e culturais) é aplicável. Assim como o princípio de non-refoulement constitui o núcleo de proteção dos refugiados (como princípio de customary law e, mais adiante, de jus cogens), aplicáveis também em outras situações no que diz respeito aos migrantes (em sua maioria os desprovidos de documentação), esse ponto assume especial importância, apesar do devido processo legal (supra);

${ }^{59} \mathrm{Em}$ alguns casos, as insuficiências dos instrumentos de proteção resultam da própria formulação de algumas de suas normas. Por exemplo, até onde a proteção dos apátridas é levada em consideração, a Convenção de 1954 relativa ao Status dos Apátridas (e, implicitamente, também na Convenção de 1961 para a Redução dos Casos de Apátridas) somente se refere a apátridas de jure, evitando que pessoas tornem-se apátridas pelo seu nascimento, mas falhando em proibir - o que talvez poderia ser mais relevante - a revogação ou perda da nacionalidade em determinadas circunstâncias; C.A. Batchelor, "Stateless Persons: Some Gaps in International Protection", 7 International Journal of Refugee Law (1995) pp. 232-255. 
assim, os direitos humanos fundamentais e a dignidade dos migrantes em situação irregular e sem documentos deve ser preservada também em face das ameaças de deportação e (ou) expulsão ${ }^{60}$. Toda pessoa nessa situação tem o direito de ser ouvida por um juiz e não ser presa ilegalmente ou arbitrariamente ${ }^{61}$.

A Convenção Internacional sobre a Proteção de Todos os Migrantes Trabalhadores e os Membros de Suas Famílias proíbe medidas de expulsão coletiva, e determina que cada caso de expulsão seja "examinado e decidido individualmente" (Artigo 22(1)), de acordo com a lei. Devido à grande

${ }^{60}$ Para uma significativa argumentação contra as arbitrariedades na deportação de migrantes, e para o apoio ao tratamento de todos os migrantes (incluindo aqueles sem documentos) com justiça, e para um senso de humanitarismo, cf. B.O. Hing, Deporting Our Souls Values, Morality and Immigrantion Policy, Cambridge, University Press, 2006, pp. 1-215. Sobre as disposições da Convenção Internacional sobre a Proteção dos Direitos de Todos os Migrantes Trabalhadores e os Membros de suas Famílias contra injustas e arbitrarias expulsões, nos termos das considerações humanitárias, cf. R. Cholewinski, Migrant Workers in International Human Rights Law Their Protection in Countries of Employment, Oxford, Clarendon Press, 1997, pp. 182-184. E, sobre a proibição de expulsão em massa de estrangeiros, cf. A.A. Cançado Trindade, "El Desarraigo como Problema de Derechos Humanos frente a la Conciencia Jurídica Universal", in Movimientos de Personas e Ideas y Multiculturalidad (Forum Deusto), vol. I, Bilbao, University of Deusto, 2003, pp. 82-84; H.G. Schermers, "The Bond between Man and State", Recht zwischen Umbruch und Bewahrung Festschrift für R. Bernhardt (eds. U. Beyerlin et alii), Berlin, Springer-Verlag, 1995, pp. 192-194; H. Lambert, "Protection against Refoulement from Europe: Human Rights Law Comes to the Rescue", 48 International and Comparative Law Quarterly (1999) pp. 515-518.

${ }^{61}$ Reassentamento, em tempo razoável, em um terceiro país, deve também ser considerado; cf. "Los Derechos y las Obligaciones de los Migrantes Indocumentados en los Países de Acogida / Protección de los Derechos Fundamentales de los Migrantes Indocumentados", 21 International Migration/Migraciones Internacionales (1983) pp. 135-136. vulnerabilidade que acompanha os migrantes em situações de irregularidade, tanto o país de origem quanto o país de admissão devem tomar medidas positivas para assegurar que todas as migrações ocorram de maneira regular ${ }^{62}$. Esse é um desafio a todos os países, e mais relevante àqueles que se dizem "democráticos". Por fim, a Convenção de 1990 deve ser apreciada em conjunto com o Pacto das Nações Unidas de 1996 sobre Direitos Civis e Políticos, assim como com as relevantes Convenções da OIT sobre o assunto ${ }^{63}$.

\section{A PROTEÇÃO DE MIGRANTES NA JURISPRUDÊNCIA INTERNACIONAL}

\section{Sistema Europeu de Direitos Humanos}

O tema "migrantes" tem marcado sua presença nos níveis normativos ou operacionais do sistema europeu de proteção aos Direitos Humanos. Assim, o Protocolo n. 4 (de 1963) para a Convenção Européia de Direitos Humanos efetivamente proíbe a expulsão coletiva de estrangeiros (Artigo 4). Ainda, no que diz respeito aos casos individuais, se a expulsão de um estrangeiro resulta na separação dos membros de sua

${ }^{62}$ Cf. ibid., p. 136.

${ }^{63}$ Precisamente, a Convenção (n. 97) de Migrações para Empregos de 1949 (Revisada), a Convenção (n. 143) sobre Trabalhadores Migrantes, assim como a Recomendação n. 151 sobre Trabalhadores Migrantes (de 1975). Para uma discussão contextual, cf., e.g., B. Boutros-Ghali, "The U.N. and the I.L.O.: Meeting the Challenge of Social Development", in Visions of the Future of Social Justice - Essays on the Occasion of the I.L.O.'s 75th Anniversary, Geneva, I.L.O., 1994, pp. 51-53. 
unidade familiar, esse ato traz consigo uma violação do Artigo 8 da Convenção Européia de Direitos Humanos; conseqüentemente, os Estados Parte desta Carta não possuem mais total independência para expulsar do seu território estrangeiros que já estabeleceram "genuínos laços" com eles ${ }^{64}$.

Os limites ao poder discricionário com que cada Estado signatário dos tratados de Direitos Humanos tem para tratar as pessoas sob suas jurisdições foram salientados, e.g., no famoso caso dos Asiáticos do Leste Africano. Nesse caso, a antiga Comissão Européia de Direitos Humanos concluiu que 25 daqueles que fizeram a queixa (os quais requereram o status de cidadãos britânicos após a independência do Quênia e Uganda para ficarem livres de controles migratórios) foram vitimados por uma nova lei britânica que impunha fim ao direito de entrada de cidadãos britânicos que não tivessem laços ancestrais com o Reino Unido. No entendimento da antiga Comissão Européia (Relatório de 1973), essa lei constituía um ato de discriminação racial o qual, por sua vez, caracterizava um "tratamento degradante" nos termos do Artigo 3 da Convenção Européia de Direitos Humanos ${ }^{65}$.

Anos depois, a mesma Comissão Européia confirmou sua posição no assunto, no caso

${ }^{64}$ H.G. Schermers, "The Bond between Man and State", Recht zwischen Umbruch und Bewahrung..., op. cit. supra n. (62), pp. 192-194.

65 Apesar do fato de que o caso nunca foi apresentado junto à Corte Européia de Direitos Humanos, e que o Comitê de Ministros não se pronunciou sobre essa violação da Convenção Européia, aguardou-se que todas as partes fossem admitidas no Reino Unido para concluir se, não mais, seria necessário tomar qualquer outra medida. D.J. Harris, M. O'Boyle and C. Warbrick, Law of the European Convention on Human Rights, Londres, Butterworths, 1995, pp. 81-82 and 695. de Abdulaziz, Cabales e Balkandali versus o Reino Unido (1983), no qual alertou que há limites para os poderes discricionários estatais no que diz respeito à legislação de imigração, tal como o fato de que um Estado não pode, e.g., implementar políticas baseadas em discriminação racial ${ }^{66}$. $\mathrm{O}$ caso foi remetido à Corte Européia pela Comissão, quando as aplicantes (Sra. Abdulaziz, Sra. Cabales e a Sra. Balkandali, legalmente e permanentemente estabelecidas no Reino Unido) foram impedidas de se juntar aos seus maridos naquele país. A Corte Européia, entretanto, no seu julgamento (1985) encontrou uma violação, não do Artigo 8 per se, mas do Artigo 8 (respeito à vida familiar e privada) junto com o Artigo 14 (proibição de discriminação), pela razão de discriminação com base no sexo ${ }^{67}$.

Adicionalmente, no caso de Abdulaziz, Cabales e Balkandali, a Corte estabeleceu uma violação do Artigo 13 da Convenção, por falta de acesso à justiça. A Corte ponderou que:

a discriminação com base no sexo da qual a Sra. Abdulaziz, a Sra. Cabales e a Sra. Balkandali foram vítimas foi resultado de normas que são, nesse aspecto, incompatíveis com a Convenção. Neste ponto, uma vez que o Reino Unido não incorporou a Convenção

${ }^{66}$ Cit. in ibid., p. 82. - A Antiga Comissão Européia preocupou-se em caracterizar a "coletiva expulsão de estrangeiros", por causa da aplicação da proibição contida no Artigo 4 do Protocolo n. 4 da Convenção Européia, como ilustrado, e.g., pelas considerações no caso $A$. et alii versus Holanda (1988), interposto por 23 reclamantes provenientes do Suriname; cf. Comissão Européia de Direitos Humanos, aplicação n. 14209/88 (decisão de 16.12.1988), em Decisions and Reports, vol. 59, Strasbourg, C.E., 1989, pp. 274-280.

\footnotetext{
${ }^{67}$ Parágrafos 83 e 86, e ponto resolutório n. 3.
} 
na sua legislação doméstica, não há um 'reparo efetivo' tal como requerido pelo Artigo $13{ }^{68}$.

No seu Parecer Concordante no caso Abdulaziz, Cabales e Balkandali, o Juiz R. Bernhardt, de modo correto, argumentou que:

o Artigo 13 deve, em minha opinião, ser pautado de um significado que seja independente da questão se qualquer outra disposição desta Convenção é, de fato, violada. Quando uma pessoa faz uma queixa que uma das disposições da própria Convenção - ou qualquer outro princípio similar contido no sistema legal - é violada por uma autoridade nacional (administrativa ou executiva), o Artigo 13 é, em meu entender, aplicável e algum reparo deve estar disponível ${ }^{69}$.

A despeito do fato que a Convenção Européia não contemplou o direito de nãoexpulsão pelos Estados Partes, muito rapidamente, nas operações da Convenção Européia, foi aceito o fato que há limites para o poder discricionário dos Estados Parte em controlar a chegada e partida de estrangeiros, em virtude das obrigações contraídas sob a própria Convenção, como ilustrado, e.g., por aquelas referentes ao Artigo 8 (sobre o direito de respeito à vida familiar e privada). Assim, embora não exista uma definição geral de "vida familiar", rapidamente uma jurisprudência foi desenvolvida a esse respeito, em face das circunstâncias de cada caso concreto. Essa jurisprudência, tendo em mente, inter alia, o princípio de proporcionalidade, estipulou de modo restrito as condições para a expulsão ${ }^{70}$.

${ }^{68}$ Parágrafo 93, e ponto resolutório n. 6.

${ }^{69}$ ECtHR, caso do Abdulaziz, Cabales e Balkandali, Julgamento (28.05.1985), Estrasburgo, C.E., 1985, Parecer Concordante do Juíz R. Bernhardt, p. 41.

70 Tendo em mente a disposição do Artigo 8 da Convenção Européia; cf. M.E. Villiger, "Expulsion and
Um estudo da proteção dos trabalhadores migrantes na Legislação Internacional dos Direitos Humanos ressaltou que, em diferentes ocasiões, a Corte Européia encontrou "uma infração do direito ao respeito à vida familiar em casos envolvendo migrantes de segundageração, quer tenham sido expulsos ou estejam sob ameaças de expulsão, por terem sido acusados de ofensas criminais em seus países de residência"71. Embora, em cada caso, as expulsões, ou ameaças de expulsão, tivessem como objetivo impedir a desordem ou crime, elas constituíam - o estudo continuou, ressaltando inter alia os julgamentos da Corte nos casos de Beldjoudi versus França (de 26.03.1992) e Moustaquim versus Bélgica (de 18.02.1991) - "meios desproporcionais de atingir esse objetivo, uma vez que os indivíduos afetados passaram parte de suas vidas, junto com suas famílias, nos países em questão e possuem pouco ou nenhum laço com seus países de origem" 72 .

Os casos Beldjoudi e Moustaquim, junto com o caso Lamguindaz versus Reino Unido (1992), são tidos atualmente como casos pioneiros nesse assunto em particular. Como argumentado em outro estudo sobre o tema, dados os laços (tais como laços familiares e sociais, escola, entendimento da língua e

the Right to Respect for Private and Family Life (Article 8 of the Convention) - An Introduction to the Commission's Case-Law", in Protecting Human Rights: The European Dimension - Studies in Honour of G.J. Wiarda/Protection des droits de l'homme: La dimension européenne Mélanges en l'honneur de G.J. Wiarda (eds. F. Matscher e H. Petzold), Köln/Berlin, C. Heymanns Verlag, 1988, pp. 657-658 and 662.

71 R. Cholewinski, Migrant Workers in International Human Rights Law - Their Protection in Countries of Employment, Oxford, Clarendon Press, 1997, p. 341.

${ }^{72}$ Ibid., pp. 341-342. 
cultura) entre migrantes de segundas gerações e seus (novos) países de residência, eles são cidadãos de facto, e sua deportação ou expulsão poderá resultar em uma violação do seu direito à vida familiar e privada (Artigo 8 da Convenção Européia) ${ }^{73}$. A proteção dos Direitos Humanos dos migrantes, sob certas circunstâncias, tem assim encontrado reconhecimento jurídico no Sistema Europeu de Direitos Humanos. Isso também ocorreu no sistema Inter-Americano de Direitos Humanos, que tem ido além do sistema Europeu nessa questão, tal como indicado a seguir.

\section{Sistema Inter-Americano de Direitos Humanos.}

A proteção dos migrantes tem, da mesma forma, marcado presença nos níveis normativos e operacionais do Sistema InterAmericano de proteção aos Direitos Humanos. Esse tema tem sido, na verdade, notavelmente presente na jurisprudência da Corte InterAmericana de Direitos Humanos nos anos recentes. Eu já havia me referido ao Julgamento da Corte (de 15.06.2005) sobre o caso da Comunidade Moiwana versus Suriname, assim como à Ordem da Corte de Medidas Provisórias de Proteção (de 18.08.2000) no caso dos Haitianos e os

73 R. Cholewinski, 'Strasbourg's 'Hidden Agenda': The Protection of Second-Generation Migrants from Expulsion under Article 8 of the European Convention of Human Rights", 12 Netherlands Quarterly of Human Rights (1994) pp. 287-306. - Para a obiter dicta da Corte Européia de Direitos Humanos na questão de "imigrantes de longo prazo", apesar de não ter sido encontrada nenhuma violação do Artigo 8 da Convenção Européia nos cas d'espèce, cf. ECtHR, caso do Uner versus Holanda, Julgamento de 18.10.2006, pars. 55-60.
Dominicanos de Origem Haitiana na República Dominicana. Nesta carta, no meu Parecer Concordante, percebi como válido alertar sobre a necessidade premente de enfrentar a tragédia contemporânea do desarraigamento. Além disso, eu ainda aleguei que

\begin{abstract}
o princípio de non-refoulement, o núcleo da proteção aos refugiados (como princípio de customary law e também de jus cogens), pode ser invocado ainda em diferentes contextos, como aqueles referentes à expulsão coletiva de (...) migrantes ou outros grupos. Esse princípio também foi definido em tratados de Direitos Humanos, como ilustrado pelo Artigo 22(8) da Convenção Americana de Direitos Humanos ${ }^{74}$.
\end{abstract}

A relevância dessa abordagem para o tema em questão, em relação à Ordem da Corte de Medidas Provisórias de Proteção no caso dos Haitianos e os Dominicanos de Origem Haitiana na República Dominicana, tem sido prontamente reconhecida em escritos da área ${ }^{75}$.

No que diz respeito ao mencionado Julgamento da Corte Inter-Americana, de 15.06.2005, no caso da Comunidade Moiwana versus Suriname, o mesmo foi seguido de uma Interpretação da Sentença (de 08.02.2006), à qual eu adicionei um Parecer Separado, na qual eu lido com os seguintes assuntos: a) a delimitação, demarcação,

${ }^{74}$ Parágrafo 7 n. 5 do meu Parecer Concordante (tradução própria), texto in: A.A. Cançado Trindade, Derecho Internacional de los Derechos Humanos Esencia y Trascendencia (Votos en la Corte Interamericana de Derechos Humanos, 1991-2006), México, Edit. Porrúa/Universidad Iberoamericana, 2007, p. 878.

75 Cf. Jaime Ruiz de Santiago, El Problema de las Migraciones Forzosas en Nuestro Tiempo, México, Instituto Mexicano de Doctrina Social Cristiana, 2003, pp. 27-30. 
titulação e retorno da terra (aos membros sobreviventes da Comunidade Moiwana e seus parentes) como uma forma de reparação; b) o dever do Estado de garantir retorno voluntário e sustentável; e c) a necessidade de reconstrução e preservação da identidade cultural dos membros da Comunidade Moiwana ${ }^{76}$.

Mais adiante, a grande adversidade submetida aos migrantes foi devidamente abordada, e devidamente enfatizada, no curso de todo os procedimentos consultivos da Corte Inter-Americana de Direitos Humanos anteriores a aqueles que conduziram à adoção das históricas $16^{\mathrm{a}}$ e $18^{\mathrm{a}}$ Opiniões Consultivas, de 1999 e 2003, respectivamente. Ambas as Opiniões foram pioneiras na jurisprudência internacional contemporânea (infra), e representam a reação da Lei a situações de violação dos Direitos Humanos em larga escala, e a pessoas que, em tempos, encontramse totalmente desprovidas de defesa. Dessa forma, é apropriado revisar, em nosso atual estágio, a contribuição dessas duas memoráveis Opiniões Consultivas para a salvaguarda dos Direitos Humanos dos migrantes desprovidos de documentos.

a) A Opinião Consultiva relativa ao Direito à Informação sobre Assistência Consular no âmbito das garantias do Devido Processo Legal (1999).

A Corte Inter-Americana emitiu, em 01.10.1999, a décima sexta Opinião

${ }^{76}$ Para o texto completo do meu Parecer Separado no casdo da Comunidade Moiwana versus Suriname (Interpretação da Sentença, de 08.02.2006), cf. A.A. Cançado Trindade, Derecho Internacional de los Derechos Humanos - Esencia y Trascendencia (Votos en la Corte Interamericana de Derechos Humanos, 19912006), México, Edit. Porrúa/Universidad Iberoamericana, 2007, pp. 683-693.
Consultiva de sua história, sobre o Direito à Informação sobre Assistência Consular no contexto do Devido Processo Legal. Nessa décima sexta Opinião Consultiva, de transcendental importância, a Corte declarou que o Artigo 36 da Convenção de Viena de 1963 sobre Relações Consulares reconhece ao estrangeiro sob detenção direitos - entre os quais encontra-se o direito à informação sobre assistência consular - aos quais correspondem deveres incumbidos aos Estados nos quais esses indivíduos se encontram detidos (independentemente de sua estrutura federal ou unitária) (pars. 84 e 140).

A Corte Inter-Americana apontou que a evolução da interpretação e aplicação do corpus júris da Legislação Internacional dos Direitos Humanos tem tido "um impacto positivo na Legislação Internacional ao afirmar e desenvolver a aptidão deste último para regular as relações entre os Estados e os seres humanos sob suas respectivas jurisdições". A Corte adotou, assim, uma "devida abordagem" ao considerar o assunto submetido a ela dentro do campo da "evolução dos direitos fundamentais da pessoa humana no Direito Internacional contemporâneo" (pars. 114-115). A Corte declarou que “Tratados de Direitos Humanos são instrumentos vívidos cuja interpretação deve seguir a evolução dos tempos e as atuais condições de vida" (par. 114). A Corte deixou claro que, em sua interpretação das normas da Convenção Americana sobre Direitos Humanos, ela deveria almejar estender a proteção a novas situações com base nos direitos preexistentes.

A Corte expressou que, para o devido processo legal ser preservado, "um recorrente deve estar apto a exercer seus direitos e 
defender seus interesses efetivamente e em completa equidade com outros recorrentes" (par. 117). Em ordem de atender seus objetivos, "o processo jurídico deve reconhecer e corrigir os fatores de real desigualdade" daqueles levados à justiça (par. 119); assim, a notificação - a pessoas desprovidas de sua liberdade no exterior - de seu direito de se comunicar com o seu cônsul, contribui para salvaguardar sua defesa e o respeito aos seus direitos processuais (pars. 121-122). O direito individual à informação sob o Artigo 36(1)(b) da Convenção de Viena sobre Relações Consulares está, portanto, de acordo com o devido processo legal (par. 124).

A não-observância ou obstrução do exercício desse direito afeta as garantias judiciais (par. 129). A Corte, nesse sentido, conectou o direito em questão a garantias, em desenvolvimento, do devido processo legal, e adicionou que sua não-observância em casos de imposição e execução de penas de morte resulta numa arbitrária privação do próprio direito à vida (nos termos do Artigo 4 da Convenção Americana de Direitos Humanos e do Artigo 6 do Pacto Internacional sobre Direitos Civis e Políticos), com todas as conseqüências jurídicas inerentes a violações desse tipo, ou seja, aquelas que dizem respeito à responsabilidade internacional do Estado e ao direito de reparação (par. 137) ${ }^{77}$.

A $16^{a}$ Opinião Consultiva da Corte, verdadeiramente pioneira, serviu como inspiração para a emergente jurisprudência internacional, in statu nascendi, sobre o

77 E cf. Pareceres Concordantes dos Juízes A.A. Cançado Trindade e S. García Ramírez, e Parecer Parcialmente Dissidente do Juíz O. Jackman. assunto $^{78}$, e tem tido sensível impacto nas práticas dos Estados da região sobre esta questão $^{79}$. O Parecer Concordante contou com uma considerável mobilização (com 8 Estados interventores, além de diversas organizações não-governamentais e indivíduos $)^{80}$. Esse histórico Parecer Concordante n. 16, ainda, revela o impacto da Legislação Internacional de Direitos Humanos na evolução do próprio Direito Internacional Público, especificamente pelo

${ }^{78}$ Como prontamente reconhecido por escritos da área; cf., e.g., G. Cohen-Jonathan, "Cour Européenne des Droits de l'Homme et droit international général (2000)", 46 Annuaire français de Droit international (2000) p. 642; M. Mennecke, "Towards the Humanization of the Vienna Convention of Consular Rights - The LaGrand Case before the International Court of Justice", 44 German Yearbook of International Law/Jahrbuch für internationales Recht (2001) pp. 430-432, 453-455, 459-460 and 467-468; L. Ortiz Ahlf, De los Migrantes - Los Derechos Humanos de los Refugiados, Asilados, Desplazados e Inmigrantes Irregulares, México, Ed. Porrúa/Univ. Iberoamericana, 2004, pp. 1-68; Ph. Weckel, M.S.E. Helali and M. Sastre, "Chronique de jurisprudence internationale", 104 Revue générale de Droit international public (2000) pp. 794 and 791; Ph. Weckel, "Chronique de jurisprudence internationale", 105 Revue générale de Droit international public (2001) pp. 764-765 and 770 .

79 Cf. A.A. Cançado Trindade, «The Humanization of Consular Law: The Impact of Advisory Opinion n. 16 (1999) of the Inter-American of Human Rights on International Case-Law and Practice», 4 Chinese Journal of International Law (2007) pp. 1-16.

${ }^{80}$ Nas audiências públicas (deste 16o. Opinião Consultiva) perante a Corte, além dos 8 Estados interventores, alguns indivíduos estiverem presentes, especificamente: 7 indivíduos representantes de 4 nacionalidades e organizações não-governamentais (atuantes no campo dos Direitos Humanos), 2 indivíduos de uma organização não-governamental trabalhando para a abolição da pena de morte, 2 representantes de uma entidade nacional de advogados, 4 Professores Universitários nas suas capacidades individuais, e 3 indivíduos representantes de uma pessoa condenada à morte. 
fato da Corte Inter-Americana ter sido o primeiro tribunal internacional a alertar que, em caso de não-observância ao Artigo 36(1) (b) da Convenção de Viena sobre Relações Consulares de 1963, isso ocorre não somente em detrimento de um Estado Parte, mas também dos seres humanos em questão ${ }^{81}$.

$\mathrm{Na}$ mesma linha de pensamento, a Opinião Consultiva n. ${ }^{\circ} 18$ abre um novo campo para a proteção de migrantes, ao reconhecer o caráter de jus cogens do princípio básico de igualdade e nãodiscriminação, e a prevalência dos direitos inerentes a seres humanos, independentemente de seus Estados de origem. A Opinião Consultiva contou com uma mobilização ainda maior (com 12 Estados acreditados, além do ACNUR, diversas organizações nãogovernamentais, instituições acadêmicas e indivíduos), a maior na história da Corte até os dias de hoje. A recente Opinião Consultiva n. 18 está, da mesma forma, causando impacto na teoria e prática da Legislação Internacional no presente domínio da proteção dos Direitos Humanos dos Migrantes ${ }^{82}$.

${ }^{81} \mathrm{Da}$ mesma forma que a CIJ subseqüentemente também admitiu, no caso LaGrand.

${ }^{82}$ Assim como devidamente admitido por escritos da área; cf., e.g., L. Hennebel, 'L'`humanisation' du Droit international des droits de l'homme - Commentaire sur l'Avis Consultatif n. 18 de la Cour Interaméricaine relatif aux droits des travailleurs migrants», 15 Revue trimestrielle des droits de l'homme (2004) n. 59, pp. 747-756; S.H. Cleveland, «Legal Status and Rights of Undocumented Migrants - Advisory Opinion OC-18/03 [of the] InterAmerican Court of Human Rights», 99 American Journal of International Law (2005) pp. 460-465; C. LalyChevalier, F. da Poïan and H. Tigroudja, «Chronique de la jurisprudence de la Cour Interaméricaine des Droits de 1'Homme (2002-2004)», 16 Revue trimestrielle des droits de l'homme (2005) n. 62, pp. 459-498. E cf. também, sobre o impacto do Opinião Consultiva n. 18 da IACtHR nos Estados Unidos, R. Smith, «Derechos Laborales y

\section{b) A Opinião Consultiva sobre a Condição Jurídica e os Direitos de Migrantes Indocumentados (2003)}

No dia 10 de março de 2002, o México requereu à Corte Inter-Americana de Direitos Humanos sua $18^{a}$ Opinião Consultiva sobre a Condição Jurídica e os Direitos dos Migrantes Indocumentados. No curso da correspondente Opinião Consultiva, a qual contou com a maior participação pública de toda a história da Corte, a Corte celebrou duas audiências públicas, a primeira em sua sede em São José da Costa Rica, em fevereiro de 2003, e a segunda fora de sua sede (pela primeira vez na sua história), em Santiago do Chile, em junho de 2003. O procedimento consultivo contou com a participação de 12 Estados acreditados (entre os quais cinco intervieram nas audiências), a Comissão Inter-Americana de Direitos Humanos, uma agência das Nações Unidas (o Alto Comissariado das Nações Unidas para Refugiados - ACNUR), e nove entidades da sociedade civil e círculos acadêmicos de diversos países da região, além do Ombudsmen (Procurador-Geral) do Conselho de Direitos Humanos da América Central.

No dia 17 de setembro de 2003, a Corte Inter-Americana de Direitos Humanos emitiu sua $18^{a}$ Opinião Consultiva (requerida pelo México), sobre a Condição Jurídica e os Direitos dos Migrantes sem Documentos, no qual considerou que os Estados devem assegurar o respeito aos Direitos Humanos à

Derechos Humanos de los Migrantes en Estatus Irregular en Estados Unidos», in Memorias del Seminario Internacional 'Los Derechos Humanos de los Migrantes' (México, Junho de 2005), México, Secretaría de Relaciones Exteriores, 2005, pp. 299-301. 
luz dos princípios gerais e básicos de igualdade e não-discriminação, e que qualquer ato discriminatório no que diz respeito à proteção e ao exercício dos Direitos Humanos deve responder à responsabilidade internacional dos Estados. Na visão da Corte, o princípio fundamental de igualdade e não-discriminação entrou no domínio do jus cogens.

A Corte adicionou que os Estados não podem discriminar ou tolerar situações discriminatórias em detrimento dos migrantes, e deve garantir o devido processo legal a qualquer pessoa, independente do seu status migratório. Este último não pode ser uma justificativa para desprover uma pessoa do exercício e do gozo dos seus direitos humanos, incluindo direitos trabalhistas. Migrantes sem documentos têm os mesmos direitos trabalhistas como quaisquer outros trabalhadores dos Estados nos quais trabalham, e esse ponto deve garantir respeito a esses direitos na prática. Os Estados não podem subordinar ou condicionar a observância do princípio de igualdade perante a lei e o princípio de não-discriminação aos objetivos de suas políticas migratórias ou outras políticas em geral.

Pareceres Individuais, adicionalmente, foram apresentados por quatro juízes, todos sendo, de modo significativo, Pareceres Concordantes. Em meu Parecer Concordante, como Presidente da Corte, ressaltei nove pontos principais, designadamente: a) o civitas maxima gentium e a universalidade da humanidade; b) as disparidades do mundo contemporâneo e a vulnerabilidade dos migrantes; c) a reação da consciência jurídica universal; d) a construção do direito subjetivo individual ao asilo; e) a posição e o papel dos princípios gerais da Lei; f) os princípios fundamentais como substratum da própria ordem legal; g) o princípio da igualdade e não-discriminação na Legislação Internacional dos Direitos Humanos; h) a emergência, o contento e o escopo do jus cogens; e i) a emergência e as obrigações erga omnes de proteção (em suas dimensões verticais e horizontais).

A $18^{\text {a }}$ Opinião Consultiva da Corte InterAmericana, sobre a Condição Jurídica e os Direitos dos Migrantes Indocumentados, já tem deixado, em todas suas implicações, um considerável impacto no continente Americano, e sua influência está fadada a irradiar-se também a outros lugares, tendo em mente a importância do assunto. Ela propõe a mesma dinâmica ou interpretação evolutiva da Legislação Internacional dos Direitos Humanos, anunciada pela Corte Inter-Americana, quatro anos atrás, no seu pioneiro $16^{\circ}$ Parecer Concordante, sobre o Direito à Informação sobre Assistência Consular no contexto do Devido Processo Legal (1999) $)^{83}$, que tem sido, desde então, uma fonte de inspiração para a jurisprudência internacional, in statu nascendi, sobre o assunto. Em 2003, a Corte Inter-Americana reiterou e expandiu em suas perspectivas de futuro, na sua $18^{\mathrm{a}}$ Opinião Consultiva, sobre a Condição Jurídica e os Direitos dos Migrantes Indocumentados, construída sobre os conceitos de jus cogens e de obrigações erga omnes de proteção.

${ }^{83}$ No pioneiro 16o. Parecer Concordante, de grande importância, a Corte Inter-Americana esclareceu que, na sua interpretação das normas da Convenção, a proteção deveria ser estendida a novas situações (como aquelas relativas à observância do direito à informação sobre assistência consular) nos termos dos direitos préexistentes (supra). 


\section{VI.A PROTEÇÃO DOS MIGRANTES} EM SISTEMAS DE RAPPORTEUR.

A proteção dos Direitos Humanos dos migrantes tem de fato se tornado uma questão-chave na agenda internacional dos Direitos Humanos nessa primeira década do século XXI. É um fato um tanto surpreendente, dada a crescente sensibilização das relações entre a intensificação dos fluxos migratórios (desde o fim dos anos 80 em diante), a crescente internacionalização do capitalismo, a crescente exploração do trabalho (gerada pelas "necessidades do capital", junto com custos humanos de desemprego e subempregos, "informalidade" nas relações de trabalho, procura por mão-de-obra barata, empobrecimento das condições de vida de grandes segmentos da população, e concentração de renda e riqueza em escala mundial $)^{84}$.

Era de esperar que, nos anos noventa, o tema fosse objeto de crescente atenção por parte dos organismos internacionais nos níveis universais (Nações Unidas) e regionais (Organização dos Estados Americanos). No nível global, lúcidas vozes de dentro do Alto Comissariado das Nações Unidas para Refugiados (ACNUR) alertaram que o ACNUR não poderia mais somente trabalhar para a proteção dos refugiados, mas também deveria levar em consideração as negações de Direitos Humanos aos deslocados internos, como também aos migrantes, e trabalhar para sua proteção, junto com aquela destinada aos refugiados ${ }^{85}$. Nesse sentido, não deve passar

${ }^{84}$ Cf., e.g., A.M. Aragonés Castañer, Migración Internacional de Trabajadores - Una Perspectiva Histórica, Mexico, Edit. Plaza y Valdés, 2004 [reimpr.], pp. 21, 23, $54,62,71-73,115-120,125-126,148$ e 154-157.

85 Jaime Ruiz de Santiago, "El Impacto en el Refugio de la Nueva Dinámica Migratoria en la Región - Retos para Asegurar la Protección de despercebido que o ACNUR, na verdade, interveio nas audiências orais perante a Corte Inter-Americana de Direitos Humanos, nos procedimentos consultivos que levaram à adoção, pela Corte, da sua $18^{\mathrm{a}}$ Opinião Consultiva sobre a Condição Jurídica e os Direitos dos Migrantes Indocumentados (de 17.09.2003) $)^{86}$.

Além disso, as organizações internacionais, impulsionadas pelo novo fenômeno da intensificação dos fluxos de migrações forçadas, decidiram - tanto as Nações Unidas e a Organização dos Estados Americanos inserir o assunto no sistema de trabalho de seus respectivos sistemas de Rapporteur. O mandato do Rapporteur Especial das Nações Unidas para os Direitos Humanos dos Migrantes foi criado em 1999, pela Resolução 1999/44 da antiga Comissão das Nações Unidas sobre Direitos Humanos (par. 3). A Resolução acreditou o Rapporteur com a tarefa de elaborar relatórios e realização de visitas a países, e ainda solicitou que ele examinasse "maneiras e meios para superar os obstáculos existentes à completa e efetiva proteção dos Direitos Humanos dos migrantes" 87 .

Refugiados", in IIHR, Primer Curso de Capacitación para Organizaciones de la Sociedad Civil sobre Protección de Poblaciones Migrantes (June 1999), México/São José da Costa Rica, UNHCR/Universidad Iberoamericana/IIHR, 2002, p. 43; Juan Carlos Murillo, "La Declaración de Cartagena, el Alto Comisionado de Naciones Unidas para los Refugiados y las Migraciones Mixtas", in Migraciones y Derechos Humanos (Agosto 2004), São José da Costa Rica, IIHR/PRODECA, 2004, pp. 174-176.

${ }^{86}$ Para os requerimentos do ACNUR perante a Corte Inter-Americana, cf. IACtHR, Series B (Pleadings, Oral Arguments and Documents), n. 18 (2003), pp. 211223 (argumento oral de 04.06.2003).

${ }^{87}$ U.N., Special Rapporteur of the [U.N.] Commission on Human Rights on the Human Rights of Migrants, doc. www.ohchr.org, 2o. parágrafo. 
A Resolução 1999/44 chamou atenção ao "grande e crescente número de migrantes no mundo" em uma "situação de vulnerabilidade" e declarou "a necessidade de uma centralizada e consistente abordagem no que diz respeito aos migrantes como um grupo vulnerável" ${ }^{\text {88 }}$. No âmbito do referido mandato, diversas séries de relatórios foram preparados e apresentados pelo Rapporteur Especial que, entre 2000 e 2005, realizou visitas a países como o Canadá, Equador, Filipinas, fronteira entre México e Estados Unidos, México, Espanha, Marrocos, Irã, Itália, Peru e Burkina Faso.

Em 2005, a Comissão das Nações Unidas de Direitos Humanos estendeu o mandato do Rapporteur Especial, prevendo a adoção de políticas apropriadas para os migrantes tendo como prioridade a proteção dos Direitos Humanos dos migrantes - declarando o dever dos Estados de prever e sancionar atos de indivíduos privados que atentem contra a vida e integridade pessoal dos migrantes, e assegurando o reconhecimento da comunidade internacional da situação de vulnerabilidade enfrentada pelos migrantes ${ }^{89}$. Esse é um importante ponto para a presente questão; de fato, substanciais e recentes estudos sobre as migrações têm focalizado a estrutura das iniciativas legais em um sistema de direito

${ }^{88} 4 .^{\circ}, 6^{\circ}$ e $7 .^{\circ}$ parágrafos perambulares.

${ }^{89}$ Cf. comentários in:E.D.Estrada Tanck, "Legislación y Políticas Públicas Mexicanas: Armonización con el Régimen Jurídico Internacional sobre Derechos Humanos de los Migrantes", in Memorias del Seminario Internacional 'Los Derechos Humanos de los Migrantes', (México, June 2005), México, Secretaría de Relaciones Exteriores, 2005, pp. 330-331; C. Villán Durán, "Los Derechos Humanos y la Inmigración en el Marco de las Naciones Unidas", in ibid., pp. 95-98. comparado $^{90}$, ou no âmbito regional (e.g., aquele da União Européia) ${ }^{91}$ - focalizando na estrutura normativa, mas sem retratar suficientemente a dramática situação de vulnerabilidade dos migrantes (estejam eles providos ou desprovidos de documentos), todos fortemente necessitados de proteção.

De fato, ainda no nível global (Nações

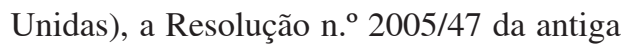
Comissão das Nações Unidas de Direitos Humanos, adotada em 19.04.2005, expressou preocupação, no seu preâmbulo, acerca do "crescente número de migrantes mundo afora", um fenômeno preocupante com um "caráter global" (par. 6), e chamou os Estados a revisar suas políticas imigratórias com uma visão de eliminar todas as práticas discriminatórias contra os migrantes e suas famílias (par. 4). Ela requereu que os Estados dessem fim às prisões arbitrárias e à privação da liberdade dos migrantes (par. 15), a prevenir a violação dos direitos humanos dos migrantes enquanto em trânsito (par. 18), e a combater e processar o tráfico internacional e o contrabando dos migrantes (que coloca suas vidas em perigo e implica "diferentes formas de servidão e exploração" - par. 19) $)^{92}$.

${ }^{90}$ Cf., inter alia, Federación Iberoamericana de Ombudsman, I Informe sobre Derechos Humanos Migraciones (coord. G. Escobar), Madri, Ed. Dykinson/ Depalma, 2003, pp. 47-420.

${ }^{91}$ Cf., e.g., P.A. Fernández Sánchez, Derecho Comunitario de la Inmigración, Barcelona, Atelier, 2006, pp. 15-325.

${ }^{92}$ A resolução encorajou os Estados Partes a implementar completamente a Convenção das Nações Unidas contra o Crime Organizado Transnacional e os dois Protocolos Adicionais, especificamente, o Protocolo contra o Contrabando de Migrantes por Terra, Mar e Ar, e o Protocolo para Prevenir, Suspender e Punir Tráfico de Pessoas, Especialmente Mulheres e Crianças, e instou os Estados que não o tenha feito a ratificá-los (par. 33). 
A Resolução n. ${ }^{\circ}$ 2005/47 lembrou, em seu preâmbulo, as contribuições das pioneiras Opiniões Consultivas no. 16 e 18 da Corte Inter-Americana de Direitos Humanos, sobre o Direito à Informação sobre Assistência Consular na Estrutura do Devido Processo Legal (1999), e sobre a Condição Jurídica e os Direitos dos Migrantes sem Documentos (2003), assim como os Julgamentos da Corte Internacional de justiça sobre os casos LaGrand (2001) e Avena e Outros Cidadãos Mexicanos $(2004)^{93}$.

No nível regional, a Comissão InterAmericana de Direitos Humanos (IAComHR), atendendo a um requerimento da Assembléia Geral da Organização dos Estados Americanos $(\mathrm{OEA})^{94}$, estabeleceu o mandato do seu Rapporteur Especial para Trabalhadores Migrantes e suas Famílias em 1997, com grande ênfase em suas situações de "vulnerabilidades especiais". De 1997 em diante, o Rapporteur Especial esteve encarregado da tarefa de monitorar a situação dos migrantes e de suas famílias na região, assim como acompanhar o dever dos Estados em protegê-los e "agir prontamente" em petições e comunicações feitas por eles. $\mathrm{O}$ Rapporteur Especial redigiu recomendações aos Estados, preparou relatórios e estudos, e realizou visitas a países da região, incluindo Estados Unidos, México, Guatemala e Costa Rica. Os tópicos de pesquisa examinados até então, em ordem de "aumentar a sensibilidade" sobre as adversidades enfrentadas pelos trabalhadores migrantes e suas famílias, incluíram discriminação em geral, racismo e

${ }^{93} 6$. $^{\circ}$ parágrafo preambular.

94 OEA, A.G. resoluções AG/RES.1404/XXVI-O/96 (de 1996) e AG/RES.1480/XXVII-0/97 (de 1997). xenofobia, devido processo legal, condições de detenção, contrabando de migrantes e tráfico de pessoas, práticas migratórias e suas conseqüências econômicas ${ }^{95}$.

\section{JUSTIÇA SOCIAL E A PREVENÇÃO DE MIGRAÇÕES FORÇADAS: O LEGADO DAS CONFERÊNCIAS DAS NAÇÕES UNIDAS}

Uma corrente dos contemporâneos escritos de direito europeu invocou a responsabilidade internacional dos Estados em ordem de declarar as práticas estatais que gerem refugiados - assim como pessoas deslocadas - como constituindo um injusto ato internacional (muito em presença do elemento de culpa lata ${ }^{96}$. A base conceitual para a construção dessa doutrina pode ser encontrada no trabalho da Comissão de Direito Internacional das Nações Unidas sobre o tema da responsabilidade dos Estados ${ }^{97}$. Uma justificativa para essa elaboração doutrinária está no fato que instrumentos internacionais de proteção dos refugiados limitaram as disposições de obrigações somente aos Estados acolhedores, mas não em relação aos Estados de origem

95 OEA, Special Rapporteurship on Migrant Workers and Their Families, Washington D.C., IAComHR, documento www.cidh.oas.org/migrants, 2007, pp. 1-10.

${ }^{96}$ P. Akhavan and M. Bergsmo, "The Application of the Doctrine of State Responsibility to Refugee Creating States", 58 Nordic Journal of International Law - Acta Scandinavica Juris Gentium (1989) pp. 243-256.

${ }^{97}$ Cf. R. Hofmann, "Refugee-Generating Policies and the Law of State Responsibility", 45 Zeitschrift für ausländisches öffentliches Recht und Völkerrecht (1985) pp. 694-713. 
dos refugiados; devido a essa descoberta, uma norma costumeira de Direito Humanitário proibindo a geração de fluxos de refugiados foi invocada ${ }^{98}$. Desse ponto em diante, as conseqüências são estabelecidas em relação ao injusto ato de produzir fluxos de refugiados - que poderia ser aplicável $a$ fortiori a repentinos fluxos migratórios também para efeitos de reparação.

Esse empreendimento doutrinário revela, na minha opinião, aspectos positivos e negativos. Por um lado, alarga o horizonte para o exame do assunto, abrangendo tanto o Estado acolhedor quanto o Estado de origem, procurando a proteção dos Direitos Humanos em ambos. Por outro lado, move-se para o âmbito de reparações com uma abordagem de Direito Privado, tentando justificar sanções a Estados que não são os únicos responsáveis por fluxos migratórios. Em um mundo "globalizado" como este dos dias atuais, carregado de desigualdades entre e dentro dos Estados, como identificar as origens de tamanha crueldade socioeconômica, como desvendar essa linha divisória, como destacar Estados (precisamente os mais pobres) responsáveis por migrações forçadas, para justificar sanções e represálias?

Esse, na minha opinião, não parece ser o caminho a ser seguido. O problema dos fluxos de migrações forçadas deve ser tratado como uma verdadeira questão global, envolvendo toda a comunidade internacional. Não pode ser abordado a partir de uma desatualizada e estrita visão bilateral (focalizando apenas nos

98 W. Czapli_ski and P. Sturma, "La responsabilité des États pour les flux de réfugiés provoqués par eux", 40 Annuaire français de Droit international (1994) pp. 156-169.
Estados acolhedores e os Estados de origem) ou uma mera perspectiva Inter-Estatal. Sendo uma questão global, traz à tona obrigações erga omnes de proteção dos migrantes vitimados. O desenvolvimento conceitual dessas obrigações - e das conseqüências jurídicas de sua quebra - permanece como uma alta prioridade para a ciência jurídica contemporânea.

Foi argumentado que, diante do fenômeno contemporâneo de migrações forçadas, a responsabilidade dos Estados individuais não podem ser dissociadas da (subsidiária) responsabilidade da comunidade internacional dos Estados como um todo ${ }^{99}$. Como as causas das migrações forçadas devem, em certas circunstâncias, corresponder a massivas violações de Direitos Humanos, uma reavaliação da base conceitual do refúgio pode levar à necessária e gradual configuração do direito de sobrevivência dos segmentos da população afetados ou em perigo ${ }^{100}$. Mais do que propriamente a sobrevivência, o que está em jogo aqui é o direito de viver com dignidade ${ }^{101}$.

Toda a questão traz à tona os imperativos da justiça social, no nível universal. E uma ênfase especial deve recair sobre a prevenção de migrações forçadas. Nesse sentido, no

${ }^{99}$ L. Peral Fernández, Éxodos Masivos, Supervivencia y Mantenimiento de la Paz, Madrid, Ed. Trotta, 2001, pp. 208.

${ }^{100}$ Ibid., pp. 72 and 79-81.

${ }^{101}$ Para estudos gerais, cf. J.G.C. van Aggelen, Le rôle des organisations internationales dans la protection $d u$ droit à la vie, Bruxelles, E. Story-Scientia, 1986, pp. 1-89; D. Prémont et alii (eds.), Le droit à la vie quarante ans après l'adoption de la Déclaration Universelle des Droits de l'Homme: Évolution conceptuelle, normative et jurisprudentielle, Genève, CID, 1992, pp. 5-91. 
nível das Nações Unidas, o sistema de aviso prévio deve ser lembrado: ele nasceu de uma proposta, no começo dos anos oitenta, pelo Rapporteur Especial para a questão dos Direitos Humanos relativos a êxodos em massa. Subseqüentemente, o tema foi relacionado aos deslocados internos ${ }^{102}$. Em 1997, o Alto Comissariado das Nações Unidas para Direitos Humanos observou que, no contexto dos êxodos em massa e os Direitos Humanos,

o termo 'prevenção' não deve ser interpretado no sentido de impedir que as pessoas abandonem uma zona ou um país, mas sim no sentido de impedir que os Direitos Humanos deteriorem-se a ponto que o abandono seja a única opção, assim como impedir (...) a adoção deliberativa de medidas para deslocar por força um grande número de pessoas, tais como expulsões em massa, deslocamentos internos e evasão domiciliar, reassentamento e repatriações forçados ${ }^{103}$.

Além do mais, os documentos finais dos ciclos recentes de Conferências Mundiais das Nações Unidas nos anos noventa contêm elementos adicionais os quais permitem-nos abordar adequadamente a questão dos fluxos populacionais como uma verdadeira questão global, situada no universo conceitual dos Direitos Humanos ${ }^{104}$. Assim, e.g., a Declaração

${ }^{102}$ Cf. U.N., documento E/CN.4/1995/CRP.1, de 30.01.1995, pp. 1-119.

${ }^{103}$ U.N., Derechos Humanos y Éxodos en Masa Informe del Alto Comisionado para los Derechos Humanos, documento E/CN.4/1997/42, de 14.01.1997, p. 4, par. 8, e cf. pp. 4-5, pars. 9-10.

${ }^{104}$ Para um relato geral cf. A.A. Cançado Trindade, "Relations between Sustainable Development and Economic, Social and Cultural Rights: Recent Developments", in International Legal Issues Arising under the United Nations Decade of International Law (eds. N. Al-Nauimi and R. Meese), Deventer, Kluwer, e Plano de Ação de Viena de 1993, adotada pela II Conferência Mundial de Direitos Humanos, convocou os Estados a garantir a proteção dos Direitos Humanos a todos os trabalhadores migrantes e membros de sua família (parte II, par. 33). O Documento Final da Conferência de Viena colocou, mais adiante, a importância de criar condições que promovam maior harmonia e tolerância entre trabalhadores migrantes e o resto da sociedade do Estado acolhedor (par. 34). Por último, convocou os Estados a ratificar, o mais breve possível, a Convenção Internacional sobre a Proteção dos Direitos de Todos os Trabalhadores Migrantes e os Membros de suas Famílias (par. 35).

A Conferência Internacional sobre Desenvolvimento e População (Cairo, 1994) abordou, obviamente, o assunto em questão, chamando por uma abordagem global ao fenômeno migratório em nível mundial (capítulo X do Plano de Ação de Cairo de 1994). A Conferência do Cairo examinou as causas das migrações, e solicitou a adoção

1995, pp. 1051-1077; A.A. Cançado Trindade, "The Contribution of Recent World Conferences of the United Nations to the Relations between Sustainable Development and Economic, Social and Cultural Rights", in Les hommes et l'environnement: Quels droits pour le vingt-et-unième siècle? - Études en hommage à Alexandre Kiss (eds. M. Prieur and C. Lambrechts), Paris, Éd. Frison-Roche, 1998, pp. 119-146; A.A. Cançado Trindade, "Sustainable Human Development and Conditions of Life as a Matter of Legitimate International Concern: The Legacy of the U.N. World Conferences", in Japan and International Law - Past, Present and Future (Symposium Internacional para Marcar o Centenário da Associação Japonesa de Direito Internacional), Haia, Kluwer, 1999, pp. 285-309; A.A. Cançado Trindade, Tratado de Direito Internacional dos Direitos Humanos, vol. III, Porto Alegre/Brasil, S.A. Fabris Ed., 2003, pp. 235-299; M.G. Schechter, United Nations Global Conferences, Londres, Routledge, 2005, pp. 95-100 and 134-139. 
de disposições em relação a trabalhadores migrantes providos ou desprovidos de documentos ${ }^{105}$.

Um ano depois, o Plano de Ação de Copenhagen de 1995, adotado pela Cúpula Mundial para o Desenvolvimento Social, ao abordar a criação de empregos produtivos e redução de desemprego, alertou sobre a necessidade de maior atenção, no nível nacional, à situação de trabalhadores migrantes e membros de suas famílias (capítulo III). Ao abordar a questão de integração social, convocou a promoção da igualdade e da justiça social, envolvendo inter alia educação básica - abrangendo também os filhos de pais migrantes - e promovendo o tratamento eqüitativo e integração de trabalhadores migratórios e os membros de suas famílias (capítulo IV).

A Cúpula Mundial de Copenhagen, mais adiante, convidou os Estados a cooperar "para reduzir as causas de migrações desprovidas de documentos" e a salvaguardar "os direitos humanos fundamentais dos migrantes sem documentos, impedindo sua exploração" e prover a eles reparações domésticas ${ }^{106}$. Ela convocou, por último, os Estados a ratificar e aplicar os instrumentos internacionais relativos a trabalhadores migrantes e os membros de suas famílias ${ }^{107}$.

${ }^{105}$ Para uma avaliação do trabalho da Conferência do Cairo de 1994 no tema das migrações internacionais, cf., e.g., S. Johnson, The Politics of Population - The International Conference on Population and Development, Cairo 1994, Londres, Earthscan, 1995, pp. 165-174.

${ }^{106}$ U.N./Centre for Human Rights, Los Derechos de los Trabajadores Migratorios (Foll. Inf. n. 24), Genebra, U.N., 1996, pp. 19-20.

${ }^{107}$ Ibid., p. 19.
A situação particular de mulheres migrantes trabalhadoras (vitimadas por violência com base no sexo) foi objeto de considerável atenção por parte da IV Conferência Mundial sobre Mulheres (Pequim, 1995). A Plataforma de Ação de Pequim de 1995, adotada pela Conferência, convidou os Estados a reconhecer a vulnerabilidade em face da violência e outras formas de tratamento degradante das mulheres migrantes, incluindo as mulheres migrantes e trabalhadoras (capítulo IV.D) ${ }^{108}$.

Por sua vez, a II Conferência Mundial sobre Assentamentos Humanos (Habitat-II, Istambul, 1996) apontou o relevante papel dos assentamentos humanos na realização dos Direitos Humanos, em particular, inter alia, o direito a uma habitação adequada e o direito ao desenvolvimento. Neste ponto, o Programa Habitat-II de 1996 formulou recomendações relativas à "segurança legal do arrendamento, à prevenção de expulsões, ao fomento de centros para refugiados e ao apoio prestado aos serviços básicos e às unidades de educação e saúde a favor dos deslocados, entre outros grupos vulneráveis" 109 .

Ainda, a Conferência das Nações Unidas contra Racismo, Descriminação Racial, Xenofobia e Intolerâncias Relacionadas (Durban, 2001) também devotou atenção especial aos trabalhadores migrantes, em particular à discriminação sofrida por eles. A Declaração e o Plano de Ação de 2001 adotados pela Conferência de Durban instou os Estados a lutar contra manifestações de marginalização generalizada de migrantes, de preconceitos raciais ou xenófobos,

\footnotetext{
${ }^{108}$ Cf. ibid., p. 20.

${ }^{109}$ U.N., Derechos Humanos y Éxodos en Masa..., op. cit. supra n. (105), p. 21, par. 61.
} 
respeitando, assim, suas obrigações nos termos dos instrumentos internacionais de Direitos Humanos, independente da situação na qual os migrantes se encontram (pars. 24 e 26).

Recentemente, a mencionada resolução 2005/47 (de 19.04.2005), da antiga Comissão das Nações Unidas de Direitos Humanos, reafirmou as disposições a respeito da proteção dos direitos dos migrantes e suas famílias, consagrada nos documentos finais adotados pelas Conferências das Nações Unidas sobre Direitos Humanos (1993), sobre População e Desenvolvimento (1994), sobre Desenvolvimento Social (1995), sobre as Mulheres (1995), e contra Racismo, Discriminação Racial, Xenofobia e Intolerâncias Relacionadas (2001) ${ }^{110}$. O Escritório do Alto Comissariado das Nações Unidas para Direitos Humanos também esteve atento a alguns dos aspectos das adversidades enfrentadas por migrantes e sua crescente necessidade de proteção ${ }^{111}$.

Por sua parte, o Comitê das Nações Unidas sobre a Eliminação de Discriminação Racial - órgão supervisor da Convenção das Nações Unidas sobre a Eliminação de Todas as Formas de Discriminação Racial - na sua recomendação geral $\mathrm{n} .^{\circ}$ 30, de 2005, alertou que "conforme a Convenção, o tratamento diferencial baseado na cidadania ou no status migratório irá constituir discriminação caso o critério para tal diferenciação, julgado à luz dos objetivos e propostas da Convenção, não seja aplicável nos termos de um intento

\footnotetext{
${ }^{110} 4 .^{\circ}$ parágrafo preambular.

${ }^{111}$ Cf. U.N., Recommended Principles and Guidelines on Human Rights and Human Trafficking - Report of the U.N. High Commissioner for Human Rights to the Economic and Social Council, U.N documento E/2002/68/ Add.1, de 20.05.2002, pp. 3-16.
}

legítimo, e não seja proporcional à realização desse intento" (par. 4). A recomendação devota uma sessão inteira (IV) ao "acesso à cidadania" (pars. 13-17) e, mais adiante, aborda as questões de prevenção e reparação dos problemas enfrentados por "trabalhadores sem cidadania" (par. 34), assim como as garantias do "acesso das vítimas a reparações legais efetivas" e seu "direito de buscar reparações justas e adequadas" pelos males sofridos (par. 18).

\section{REFLEXÕES FINAIS SOBRE O ASSUNTO}

Como uma questão verdadeiramente global, o fenômeno das migrações forçadas requer grande preocupação em nível universal para assegurar a prevalência dos direitos dos migrantes e de suas famílias. Um papel relevante é reservado às políticas públicas, assim como à mobilização de entidades da sociedade civil para mitigar seus sofrimentos e melhorar as condições da vida diária dos migrantes. Essas entidades podem, em primeiro lugar, ajudar os órgãos de assistência e proteção na própria identificação das distintas características assumidas pelo fenômeno migratório em diferentes países ${ }^{112}$. Em segundo lugar, elas podem denunciar situações de flagrantes violações dos Direitos Humanos dos migrantes ${ }^{113}$.

${ }^{112}$ Sobre as distintas características, e.g., em alguns países Latino-Americanos, cf. IIHR, Balance y Perspectivas del Fenómeno Migratorio en América Latina: Punto de Aproximación desde la Perspectiva de la Protección de los Derechos Humanos, São José da Costa Rica, IIHR, 1998, p. 2 (circulação restrita).

${ }^{113}$ Cf., e.g., J.E. Méndez, A Proposal for Action on Sudden Forced Migrations, São José da Costa Rica, IIHR, 1997, p. 10 (circulação restrita). 
Em terceiro lugar, elas podem prestar assistência em ações de emergência. Quarto, podem ajudar a promover o fortalecimento institucional para enfrentar o fenômeno migratório, e capacitar as pessoas afetadas ${ }^{114}$. Por último, para fins de educação em Direitos Humanos, elas podem ajudar a erradicar xenofobia e outros preconceitos existentes nas sociedades nacionais. Avanços nesse domínio serão atingidos, como já apontado, na atmosfera da solidariedade humana. Sob essa perspectiva, "construções" recentes, tais como migrantes "irregulares" - ou, pior, “ilegais" - são um tanto negativas ${ }^{115}$, e não ajudam em nada na procura por soluções duráveis aos problemas enfrentados pelos migrantes mundo afora.

Os seres humanos não se tornam desprovidos de seus direitos em razão de seu status migratório ou qualquer outra circunstância; pode-se prever os Direitos Humanos dos desarraigados e - contrário a aquilo que alguns tentam fazer com que outros acreditem - o princípio de nonrefoulement pertence ao domínio do jus cogens $^{116}$. O poder discricionário dos Estados tem seus limites, e suas políticas de deportação e expulsão deve respeitar as normas imperativas do Direito Internacional.

${ }^{114}$ Cf. IIHR, Papel Actual de las Organizaciones de la Sociedad Civil en Su Trabajo con las Poblaciones Migrantes en el Continente, São José da Costa Rica, IIHR, 1998, pp. 1-14 (circulação restrita).

${ }^{115}$ L. Ortiz Ahlf, "Derechos Humanos de los Migrantes", 35 Jurídica - Anuario del Departamento de Derecho de la Universidad Iberoamericana (2005) pp. 14, 19, 23 e 26-29.

${ }^{116}$ A.A. Cançado Trindade, "El Desarraigo como Problema de Derechos Humanos frente a la Conciencia Jurídica Universal", in Movimientos de Personas e Ideas y Multiculturalidad (Forum Deusto), vol. I, Bilbao, Universidade de Deusto, 2003, pp. 87-103.
No lado positivo, há, nos dias de hoje, uma maior consciência da crescente necessidade de proteção de migrantes mundo afora. As Conferências das Nações Unidas, durante os anos noventa e na passagem do século, contribuíram decisivamente para criar essa nova conscientização. Elas deram grande ênfase nas necessidades de proteção de pessoas e segmentos da população em situações de vulnerabilidade. Atualmente, seminários e encontros de especialistas governamentais e não-governamentais são realizados cada vez mais freqüentemente, na busca de soluções relativas aos imperativos de proteção dos migrantes ${ }^{117}$. Ainda, grande preocupação em nível universal é necessária, uma vez que a proteção dos migrantes, em crescentes números em distintas partes do globo, tem se tornado uma preocupação legítima da comunidade internacional como um todo.

É tranqüilizador que a Declaração do Milênio das Nações Unidas do ano 2000 tenha sido atenciosa o suficiente para incluir (par. 25) um chamado

a tomar medidas para assegurar o respeito e proteção dos Direitos Humanos dos migrantes, trabalhadores migrantes e suas famílias, a eliminar os crescentes atos de racismo e xenofobia em diversas sociedades e a promover maior harmonia e tolerância em todas as sociedades.

${ }^{117}$ Cf., e.g., entre outras inciativas: Instituto Internacional de Direito Humanitário (IIHL), Conflict Prevention - The Humanitarian Perspective (Proceedings, August/September 1994), San Remo, IIHL, 1994, pp. 7-185; Universidad de Sevilla, La Asistencia Humanitaria en el Derecho Internacional Contemporáneo, Sevilla, Univ. de Sevilla, 1997, pp. 1-74 (circulação interna); XVI Cumbre Iberoamericana, Compromiso de Montevideo sobre Migraciones y Desarrollo, de 05.11.2006, pp. 1-10 (circulação interna). 
Meia década depois, em setembro de 2005, o Documento das Nações Unidas resultante da Cúpula Mundial de 2005, também de maneira tranqüilizadora, alargou a expressiva referência à questão das migrações (pars. 61-63), relacionando migração ao desenvolvimento (par. 61), e reafirmando "nossa determinação para tomar medidas que garantam proteção e respeito aos Direitos Humanos dos migrantes, trabalhadores migrantes e membros de suas famílias" (par. 62).

Avanços nesse domínio, entretanto, somente serão atingidos com uma radical mudança de mentalidade, e uma maior consciência das crescentes necessidades para proteger os direitos básicos dos migrantes. Em qualquer escala de valores, considerações de ordem humanitária deve prevalecer sobre aquelas de ordem econômica ou financeira, sobre o alegado "protecionismo" do "mercado global", e sobre rivalidades entre grupos. Há, definitivamente, uma crescente necessidade para situar os seres humanos no seu devido lugar, certamente acima de capitais, bens e serviços. Esse é um dos maiores desafios do mundo "globalizado" no qual vivemos, da perspectiva dos Direitos Humanos.

Deixe-me concluir essa aula inaugural, aqui, no Instituto Internacional de Direitos Humanos em Estrasburgo, reafirmando o que eu sustentei, dois anos atrás, no meu Curso Geral sobre Direito Internacional Público, apresentado na Academia de Direito Internacional de Haia, no sentido de que, no meu entendimento, avanços na Lei são, em última instância, devidos à consciência humana, a última fonte material de toda a Lei $^{118}$. Muitos séculos foram necessários para

${ }^{118}$ A.A. Cançado Trindade, "International Law for Humankind: Towards a New Jus Gentium - General Course on Public International Law - Part I", 316 Recueil que os seres humanos ficassem conscientes do problema do tempo, para adquirir uma "consciência histórica""119. E, desde os tempos heróicos da Ilíada de Homero na Grécia Antiga, foram necessários alguns outros séculos para os seres humanos adquirirem "consciência ética", ou seja, perceber que eles eram responsáveis pela sua própria conduta (cada um sendo “juiz" próprio de sua conduta) e pela forma que eles tratam os outros, seres humanos entre iguais.

Nesse sentido, no século XVIII, Immanuel Kant conceituava consciência como um "tribunal interno" de cada indivíduo como um "ser moral" "120. Séculos antes, a emergência da consciência humana ajudou a enfrentar com a razão a chamada "luta pela existência"121, a velha luta pela sobrevivência. A recta ratio presente nos escritos dos chamados "pais fundadores" do Direito das Gentes nos séculos XVI e XVII (tais como F. de Vitoria, F. Suárez, H. Grotius e outros), ao colocar o civitas maxima gentium em apoio à jus communications mundo afora, e ao propor a essencial unidade da humanidadeessa recta ratio do pensamento e escrita escolásticos deve-se aos gregos antigos (Platão e Aristóteles), correspondendo aos seus orthos $\log ^{122}$.

des Cours de l'Académie de Droit International de la Haye (2005) pp. 177-202.

${ }^{119}$ Ernst Cassirer, Essai sur l'homme, Paris, Éd. de Minuit, 1975, pp. 243-244.

${ }^{120}$ Particularmente no seu Fondements de la métaphysique des moeurs (1785); an cf. I. Kant, [Critique de] la raison pratique, Paris, PUF, 1963 [reed.], p. 201.

${ }^{121}$ Karl Popper, In Search of a Better World, Londres, Routledge, 2000 [reimpressão], p. 28.

${ }^{122}$ A.A. Cançado Trindade, "International Law for Humankind: Towards a New Jus Gentium...", op. cit. supra n. (120), Parte I, pp. 40-42 e 179-184. 
É a consciência humana que melhor governa as relações entre os seres humanos, quer seja individualmente ou entre grupos. É a consciência jurídica universal que guia o Direito Internacional, como sua derradeira fonte material ${ }^{123}$, que o move adiante, para responder às crescentes necessidades de proteção do ser humano e para alcançar o objetivo básico de realização da justiça. Estou confidente que essa Sessão de Estudos Anual de 2007 do querido Instituto Internacional de Direitos Humanos aqui em Estrasburgo irá contribuir para a prise de conscience para alcançar a crescente necessidade de garantir os Direitos Humanos dos migrantes mundo afora.

Brasília, 20 abril de 2007.

\section{REFERÊNCIAS}

ACNUR, The State of the World's Refugees Fifty Years of Humanitarian Action, Oxford, UNHCR/Oxford University Press, 2000, p. 9.

AKHAVAN, P. and BERGSMO, M. "The Application of the Doctrine of State Responsibility to Refugee Creating States", 58 Nordic Journal of International Law - Acta Scandinavica Juris Gentium (1989) pp. 243-256.

ARAGONÉS CASTAÑER, A.M. Migración Internacional de Trabajadores - Una Perspectiva Histórica, Mexico, Edit. Plaza y Valdés, 2004 [reimpr.], pp. 21, 23, 54, 62, 71-73, 115-120, 125-126, 148 e 154-157.

ARENDT, H. La tradition cachée, Paris, Ch. Bourgois Ed., 1987 (orig. ed. 1946).

48 Boletim da Faculdade de Direito da Universidade de Coimbra (1999-2000).

\footnotetext{
${ }^{123}$ Ibid., pp. 177-202.
}

BATCHELOR, C.A. "Stateless Persons: Some Gaps in International Protection", 7 International Journal of Refugee Law (1995) pp. 232-255.

BERGALLI, R. (Coord.). Flujos Migratorios y Su (Des)control, Barcelona, OSPDH/Anthropos Edit., 2006.

BORDES-BENAYOUN, C. and SCHNAPPER, D. Diasporas et nations, Paris, O. Jacob Ed., 2006.

BOUTROS-GHALI, B. "The U.N. and the I.L.O.: Meeting the Challenge of Social Development", in Visions of the Future of Social Justice - Essays on the Occasion of the I.L.O.'s 75th Anniversary, Geneva, I.L.O., 1994, pp. 51-53.

CANÇADO TRINDADE, A.A. Tratado de Direito Internacional dos Direitos Humanos, vol. III, Porto Alegre/Brasil, S.A. Fabris Ed., 2003, pp. 235-299; M.G. Schechter, United Nations Global Conferences, Londres, Routledge, 2005.

CANÇADO TRINDADE, A.A.

"Aproximaciones y Convergencias Revisitadas: Diez Años de Interacción entre el Derecho Internacional de los Derechos Humanos, el Derecho Internacional de los Refugiados, y el Derecho Internacional Humanitario (De Cartagena/1984 a San José/1994 y México/2004)", in Memoria del Vigésimo Aniversario de la Declaración de Cartagena sobre Refugiados (1984-2004), São José da Costa Rica, UNHCR, 2005, pp. 139-191. CANÇADO TRINDADE, A.A. "Derecho Internacional de los Derechos Humanos, Derecho Internacional de los Refugiados y Derecho Internacional Humanitario: Aproximaciones y Convergencias", in 10 Años de la Declaración de Cartagena sobre Refugiados - Memoria del Coloquio Internacional (São José da Costa Rica, Dec. 1994), São José da Costa Rica, IIDH/UNHCR, 1995, pp. 77-168. 
CANÇADO TRINDADE, A.A. "El Desarraigo como Problema de Derechos Humanos frente a la Conciencia Jurídica Universal", in Movimientos de Personas e Ideas y Multiculturalidad (Forum Deusto), vol. I, Bilbao, University of Deusto, 2003.

CANÇADO TRINDADE, A.A. "El Desarraigo como Problema de Derechos Humanos frente a la Conciencia Jurídica Universal", in Movimientos de Personas e Ideas y Multiculturalidad (Forum Deusto), vol. I, Bilbao, Universidade de Deusto, 2003.

\section{CANÇADO TRINDADE, A.A. "Human}

Development and Human Rights in the International Agenda of the XXIst Century", in Human Development and Human Rights Forum (Agosto 2000), São José da Costa Rica, UNDP, 2001, pp. 23-38.

CANÇADO TRINDADE, A.A. "International Law for Humankind: Towards a New Jus Gentium - General Course on Public International Law - Part I", 316 Recueil des Cours de l'Académie de Droit International de la Haye (2005) pp. 177-202.

CANÇADO TRINDADE, A.A. "International Law for Humankind: Towards a New Jus Gentium...", op. cit. supra n. (120), Parte I, pp. 40-42 e 179-184.

CANÇADO TRINDADE, A.A. "Prefácio" para: V.O. Batista, União Européia: Livre Circulação de Pessoas e Direito de Asilo, Belo Horizonte/ Brasil, Edit. Del Rey, 1998.

CANÇADO TRINDADE, A.A. "Relations between Sustainable Development and Economic, Social and Cultural Rights: Recent Developments", in International Legal Issues Arising under the United Nations Decade of International Law (eds. N. Al-Nauimi and R. Meese), Deventer, Kluwer, 1995, pp. 1051-1077.

CANÇADO TRINDADE, A.A. "Sustainable Human Development and Conditions of Life as a Matter of Legitimate International Concern: The Legacy of the U.N. World Conferences", in Japan and International Law - Past, Present and Future (Symposium Internacional para Marcar o Centenário da Associação Japonesa de Direito Internacional), Haia, Kluwer, 1999.
CANÇADO TRINDADE, A.A. "The Contribution of Recent World Conferences of the United Nations to the Relations between Sustainable Development and Economic, Social and Cultural Rights", in Les hommes et l'environnement: Quels droits pour le vingt-etunième siècle? - Études en hommage à Alexandre Kiss (eds. M. Prieur and C. Lambrechts), Paris, Éd. Frison-Roche, 1998.

CANÇADO TRINDADE, A.A. "The Humanization of Consular Law: The Impact of Advisory Opinion n. 16 (1999) of the InterAmerican of Human Rights on International Case-Law and Practice", 4 Chinese Journal of International Law (2007) pp. 1-16.

CANÇADO TRINDADE, A.A. "The

Humanization of Consular Law: The Impact of Advisory Opinion n. 16 (1999) of the InterAmerican of Human Rights on International Case-Law and Practice", 4 Chinese Journal of International Law (2007) pp. 1-16.

CANÇADO TRINDADE, A.A. Derecho Internacional de los Derechos Humanos Esencia y Trascendencia (Votos en la Corte Interamericana de Derechos Humanos, 19912006), Mexico, Edit. Porrúa/Universidad Iberoamericana, 2007.

CANÇADO TRINDADE, A.A. Derecho Internacional de los Derechos Humanos Esencia y Trascendencia (Votos en la Corte Interamericana de Derechos Humanos, 19912006), Mexico, Edit. Porrúa/Universidad Iberoamericana, 2007, pp. 15-27.

\section{CANÇADO TRINDADE, A.A. Derecho} Internacional de los Derechos Humanos Esencia y Trascendencia (Votos en la Corte Interamericana de Derechos Humanos, 19912006), México, Edit. Porrúa/Universidad Iberoamericana, 2007.

CANÇADO TRINDADE, A.A. Elementos para un Enfoque de Derechos Humanos del Fenómeno de los Flujos Migratorios Forzados (Estudo de Julho de 1998 preparado para o IIHR), Cidade da Guatemala, OIM/IIDH, Set. 2001, pp. 1-57. 
CASSIRER, E. Essai sur l'homme, Paris, Éd. de Minuit, 1975, pp. 243-244.

CASTLES, S. and KOSACK, G. Los

Trabajadores Inmigrantes y la Estructura de Clases en Europa Occidental, México, FCE, 1984, pp. 11-565.

VISSCHER, Ch. De. Théories et réalités en Droit international public, 4o. rev. ed., Paris, Pédone, 1970, pp. 18-32 et seq.

CHOLEWINSKI, R. "Strasbourg's 'Hidden Agenda': The Protection of Second-Generation Migrants from Expulsion under Article 8 of the European Convention of Human Rights", 12 Netherlands Quarterly of Human Rights (1994) pp. 287-306.

\section{CHOLEWINSKI, R. Migrant Workers in} International Human Rights Law - Their

Protection in Countries of Employment, Oxford, Clarendon Press, 1997.

CHOLEWINSKI, R. Migrant Workers in International Human Rights Law - Their

Protection in Countries of Employment, Oxford, Clarendon Press, 1997.

CLEVELAND, S.H. «Legal Status and Rights of Undocumented Migrants - Advisory Opinion OC-18/03 [of the] Inter-American Court of Human Rights», 99 American Journal of International Law (2005) pp. 460-465.

COHEN-JONATHAN, G. "Cour Européenne des Droits de l'Homme et droit international général (2000)", 46 Annuaire français de Droit international (2000).

CRÉPEAU, F. Droit d'asile - De l'hospitalité aux contrôles migratoires, Bruxelles, Bruylant/ Éd. Université de Bruxelles, 1995.

CZAPLIKI, W. and STURMA, P. «La responsabilité des États pour les flux de réfugiés provoqués par eux», 40 Annuaire français de Droit international (1994) pp. 156-169.

DENG, F.M. Internally Displaced Persons (Relatório Interino), N.Y., RPG/DHA, 1994, p. 21; e cf. U.N., doc. E/CN.4/1995/50/Add.1, de 03.10.1994, p. 34.
DENG, F.M. Protecting the Dispossessed - A Challenge for the International Community, Washington D.C., Brookings Institution, 1993.

DOMENACH, H. and PICOUET, M. Les migrations, Paris, PUF, 1995.

DOMENACH, J.-M. Le retour du tragique, Paris, Éd. Seuil, 1967.

FERNÁNDEZ SÁNCHEZ, P.A. Derecho Comunitario de la Inmigración, Barcelona, Atelier, 2006, pp. 15-325.

FROST, M. "Thinking Ethically about Refugees: A Case for the Transformation of Global Governance", in ibid., pp. 128-129.

GREENWOOD ARROYO, M. and RUIZ OPORTA, R. Migrantes Irregulares, Estrategias de Sobrevivencia y Derechos Humanos: Un Estudio de Casos, São José da Costa Rica, IIHR, 1995.

HARRIS, D.J.; O'BOYLE, M. and WARBRICK, C. Law of the European Convention on Human Rights, Londres, Butterworths, 1995, pp. 81-82 and 695.

HENNEBEL, L. «L’'humanisation’ du Droit international des droits de l'homme Commentaire sur l'Avis Consultatif n. 18 de la Cour Interaméricaine relatif aux droits des travailleurs migrants», 15 Revue trimestrielle des droits de l'homme (2004) n. 59, pp. 747-756.

HING, B.O. Deporting Our Souls - Values, Morality and Immigrantion Policy, Cambridge, University Press, 2006.

HOFMANN, R. "Refugee-Generating Policies and the Law of State Responsibility", 45 Zeitschrift für ausländisches öffentliches Recht und Völkerrecht (1985) pp. 694-713.

HUNE, S. and NIESSEN, J. "Ratifying the U.N. Migrant Workers Convention: Current Difficulties and Prospects", 12 Netherlands Quarterly of Human Rights (1994

IACtHR, Series B (Pleadings, Oral Arguments and Documents), n. 18 (2003), pp. 211-223 (argumento oral de 04.06.2003).

JOHNSON, S. The Politics of Population - The International Conference on Population and Development, Cairo 1994, Londres, Earthscan, 1995, pp. 165-174. 
KÄLIN, W. Guiding Principles on Internal Displacement-Annotations, Washington D.C., ASIL/Brookings Institution, 2000, pp. 1-276.

KANT, I. [Critique de] la raison pratique, Paris, PUF, 1963 [reed.], p. 201.

KANT, I. Fondements de la métaphysique des moeurs (1785).

La Nueva Dimensión de las Necesidades de Protección del Ser Humano en el Inicio del Siglo XXI (eds. A.A. Cançado Trindade and J. Ruiz de Santiago), 4a. rev. ed., São José da Costa Rica, ACNUR, 2006, pp. 33-92.

LALY-CHEVALIER, C. ; POÏAN, F. Da, and TIGROUDJA, H. «Chronique de la jurisprudence de la Cour Interaméricaine des Droits de l'Homme (2002-2004)», 16 Revue trimestrielle des droits de l'homme (2005) n. 62, pp. 459-498.

LAMBERT, H. "Protection against Refoulement from Europe: Human Rights Law Comes to the Rescue", 48 International and Comparative Law Quarterly (1999).

LENGELLÉ-TARDY, M. L'esclavage moderne, Paris, PUF, 1999, pp. 26, e 116, cf. pp. 97-98.

LIPPOLIS, L. Dai Diritti dell'Uomo ai Diritti dell'Umanità, Milano, Giuffrè, 2002, pp. 21-23 e 154-155.

LUCAS, J. de El Concepto de Solidaridad, 2nd. ed., Mexico, Fontamara, 1998.

MARITAIN, J. Los Derechos del Hombre y la Ley Natural, Buenos Aires, Ed. Leviatán, 1982 (reimpr.).

MÉNDEZ, J.E. A Proposal for Action on Sudden Forced Migrations, São José da Costa Rica, IIHR, 1997, p. 10 (circulação restrita).

MENNECKE, M. "Towards the Humanization of the Vienna Convention of Consular Rights The LaGrand Case before the International Court of Justice", 44 German Yearbook of International Law/Jahrbuch für internationales Recht (2001) pp. 430-432, 453-455, 459-460 and 467-468.

MURILLO, J. C. "La Declaración de Cartagena, el Alto Comisionado de Naciones Unidas para los Refugiados y las Migraciones Mixtas", in Migraciones y Derechos Humanos (Agosto 2004), São José da Costa Rica, IIHR/ PRODECA, 2004, pp. 174-176.
OGATA, S. Challenges of Refugee Protection (Declaração na Universidade de Havana, 11.05.2000), Havana/Cuba, ACNUR, 2000, pp. 7-9 (circulação interna).

OGATA, S. Los Retos de la Protección de los Refugiados (Declaração no Ministério das Relações Exteriores do Mexico, 29.07.1999), Cidade do México, ACNUR, 1999, p. 11 (circulação interna).

ORTIZ AHLF, L. "Derechos Humanos de los Migrantes", 35 Jurídica - Anuario del Departamento de Derecho de la Universidad Iberoamericana (2005) pp. 14, 19, 23 e 26-29.

ORTIZ AHLF, L. De los Migrantes - Los Derechos Humanos de los Refugiados, Asilados, Desplazados e Inmigrantes Irregulares, México, Ed. Porrúa/Univ. Iberoamericana, 2004, pp. 1-68.

PERAL FERNÁNDEZ, L. Éxodos Masivos, Supervivencia y Mantenimiento de la Paz, Madrid, Ed. Trotta, 2001.

Ph. Ségur, La crise du droit d'asile, Paris, PUF, 1998.

$\mathrm{Ph}$. Weckel, "Chronique de jurisprudence internationale", 105 Revue générale de Droit international public (2001) pp. 764-765 and 770.

$\mathrm{Ph}$. Weckel, M.S.E. Helali and M. Sastre, «Chronique de jurisprudence internationale», 104 Revue générale de Droit international public (2000) pp. 794 and 791.

POPPER, K. In Search of a Better World, Londres, Routledge, 2000 [reimpressão], p. 28.

PRÉMONT, D. et alii (eds.), Le droit à la vie quarante ans après l'adoption de la Déclaration Universelle des Droits de l'Homme: Évolution conceptuelle, normative et jurisprudentielle, Genève, CID, 1992.

Princípios das Nações Unidas sobre Deslocados Internos, cf. C. Phuong, The International Protection of Internally Displaced Persons, Cambridge, University Press, 2004.

SANTIAGO, J. R. de El Problema de las Migraciones Forzosas en Nuestro Tiempo, México, Instituto Mexicano de Doctrina Social Cristiana, 2003, pp. 27-30.

SANTIAGO, J. R. de. Migraciones Forzadas - Derecho Internacional y Doctrina Social de la Iglesia, México, Instituto Mexicano de Doctrina Social Cristiana, 2004, pp. 9-82. 
SANTIAGO, J. R. "Derechos Humanos,

Migraciones y Refugiados: Desafios en los Inicios del Nuevo Milenio", in III Encuentro de Movilidad Humana: Migrante y RefugiadoMemoria (Setembro 2000), São José da Costa Rica, UNHCR/IIHR, 2001, pp. 37-72.

SANTIAGO, J. R. "El Impacto en el Refugio de la Nueva Dinámica Migratoria en la Región Retos para Asegurar la Protección de Refugiados", in IIHR, Primer Curso de Capacitación para Organizaciones de la Sociedad Civil sobre Protección de Poblaciones Migrantes (June 1999), México/São José da Costa Rica, UNHCR/Universidad Iberoamericana/IIHR, 2002, p. 43.

SANTIAGO, J. R. El Problema de las Migraciones Forzosas en Nuestro Tiempo, Mexico, IMDSC, 2003.

SCHERMERS, H.G. "The Bond between Man and State", Recht zwischen Umbruch und Bewahrung - Festschrift für R. Bernhardt (eds. U. Beyerlin et alii), Berlin, Springer-Verlag, 1995.

SCHERMERS, H.G. "The Bond between Man and State", Recht zwischen Umbruch und Bewahrung..., op. cit. supra n. (62), pp. 192-194.

SCHMEIDL, S. "The Early Warning of Forced Migration: State or Human Security?", in Refugees and Forced DisplacementInternational Security, Human Vulnerability, and the State (eds. E. Newman and J. van Selm), Tokyo, Universidade das Nações Unidas, 2003.

SEBASTIÁN, L. de. La Solidaridad, Barcelona, Ed. Ariel, 1996.

SMITH, R. «Derechos Laborales y Derechos Humanos de los Migrantes en Estatus Irregular en Estados Unidos», in Memorias del Seminario Internacional 'Los Derechos Humanos de los Migrantes' (México, Junho de 2005), México, Secretaría de Relaciones Exteriores, 2005, pp. 299-301.

TANCK, E.D.E. "Legislación y Políticas Públicas Mexicanas: Armonización con el Régimen Jurídico Internacional sobre Derechos Humanos de los Migrantes", in Memorias del Seminario Internacional 'Los Derechos Humanos de los Migrantes', (México, June
2005), México, Secretaría de Relaciones Exteriores, 2005, pp. 330-331.

U.N., Derechos Humanos y Éxodos en MasaInforme del Alto Comisionado para los

Derechos Humanos, documento E/ CN.4/1997/42, de 14.01.1997, p. 4, par. 8, e cf. pp. 4-5, pars. 9-10.

U.N./Centre for Human Rights, Los Derechos de los Trabajadores Migratorios (Foll. Inf. n. 24), Genebra, U.N., 1996, pp. 19-20.

UNHCR, Memoria del Vigésimo Aniversario de la Declaración de Cartagena sobre los Refugiados (1984-2004), Mexico City/São José da Costa Rica, UNHCR, 2005, pp. 385-398.

VAN AGGELEN, J.G.C. Le rôle des organisations internationales dans la protection du droit à la vie, Bruxelles, E. Story-Scientia, 1986.

VAN HEAR, N. New Diasporas - The Mass Exodus, Dispersal and Regrouping of Migrant Communities, London, UCL Press, 1998.

VILLÁN DURÁN, C. “Los Derechos Humanos y la Inmigración en el Marco de las Naciones Unidas", in ibid., pp. 95-98.

VILLIGER, M.E. "Expulsion and the Right to Respect for Private and Family Life (Article 8 of the Convention) - An Introduction to the Commission's Case-Law", in Protecting Human Rights: The European Dimension - Studies in Honour of G.J. Wiarda / Protection des droits de l'homme: La dimension européenne - Mélanges en l'honneur de G.J. Wiarda (eds. F. Matscher e H. Petzold), Köln/Berlin, C. Heymanns Verlag, 1988.

WEIL, S. The Need for Roots, London/N.Y., Routledge, 1952 (reimpressa 1995).

WEINER, M. "Ethics, National Sovereignty and the Control of Immigration", 30 International Migration Review (1996).

WIESEL, E. L'oublié, Paris, Éd. Seuil, 1989.

WIESEL, E. O Tempo dos Desenraizados (Le temps des déracinés, 2003), Rio de Janeiro, Edit. Record, 2004. 